\title{
SIRT1 Activation by Natural Phytochemicals: An Overview
}

\author{
Concetta Iside, Marika Scafuro, Angela Nebbioso ${ }^{\star t}$ and Lucia Altucci ${ }^{* t}$ \\ Department of Precision Medicine, University of Campania "Luigi Vanvitelli", Naples, Italy
}

Sirtuins are class III histone deacetylases, whose enzymatic activity is dependent on NAD as a cofactor. Sirtuins are reported to modulate numerous activities by controlling gene expression, DNA repair, metabolism, oxidative stress response, mitochondrial function, and biogenesis. Deregulation of their expression and/or action may lead to tissue-specific degenerative events involved in the development of several human pathologies, including cancer, neurodegeneration, and cardiovascular disease. The most studied member of this class of enzymes is sirtuin 1 (SIRT1), whose expression is associated with increasing insulin sensitivity. SIRT1 has been implicated in both tumorigenic and anticancer

OPEN ACCESS

Edited by: Cecilia Battistelli, Sapienza University of Rome, Italy

Reviewed by: Narasimham L. Parinandi, The Ohio State University,

United States

Carmen Jeronimo,

Portuguese Oncology Institute,

Portugal

*Correspondence:

Angela Nebbioso

angela.nebbioso@unicampania.it Lucia Altucci

lucia.altucci@unicampania.it

${ }^{+}$These authors share last authorship

Specialty section: This article was submitted to Translational Pharmacology, a section of the journa Frontiers in Pharmacology

Received: 14 April 2020

Accepted: 27 July 2020

Published: 07 August 2020

Citation:

Iside C, Scafuro M, Nebbioso A and Altucci L (2020) SIRT1 Activation by Natural Phytochemicals: An Overview.

Front. Pharmacol. 11:1225. doi: 10.3389/fphar.2020.01225 processes, and is reported to regulate essential metabolic pathways, suggesting that its activation might be beneficial against disorders of the metabolism. Via regulation of p53 deacetylation and modulation of autophagy, SIRT1 is implicated in cellular response to caloric restriction and lifespan extension. In recent years, scientific interest focusing on the identification of SIRT1 modulators has led to the discovery of novel small molecules targeting SIRT1 activity. This review will examine compounds of natural origin recently found to upregulate SIRT1 activity, such as polyphenolic products in fruits, vegetables, and plants including resveratrol, fisetin, quercetin, and curcumin. We will also discuss the potential therapeutic effects of these natural compounds in the prevention and treatment of human disorders, with particular emphasis on their metabolic impact.

Keywords: sirtuin 1, natural compounds, oxidative stress, human disorders, polyphenols

\section{INTRODUCTION}

Epigenetic modifications are associated with genome stability, gene transcription, and metabolic regulation. Acetylation is one of the most characterized histone modifications. Histone acetyltransferase (HAT) and histone deacetylase (HDAC) enzymes control the levels of histone acetylation, modulating gene expression (Cavalli and Heard, 2019).

Sirtuins (SIRT) 1-7 are enzymes classified as class III HDACs. They exhibit different subcellular localizations: SIRT1, SIRT6, and SIRT7 are nuclear (although SIRT1 isoforms were also identified in

\footnotetext{
Abbreviations: SIRT1, Sirtuin 1; HATs, Histone acetyl transferases; HDACs, Histone deacetylases; ROS, Reactive oxygen species; PPAR, Receptor peroxisome proliferator-activated receptor; NRF, Nuclear respiratory factor; TFAM, Mitochondrial transcription factor A; SOD, Superoxide dismutase; TNF- $\alpha$, Tumor necrosis factor $\alpha$; IAP, Apoptosis protein inhibitor; Bcl-2, B-cell lymphoma-2 family; MnSOD, Manganese superoxide dismutase; RSV, Resveratrol; Que, Quercetin; oxLDL, Oxidized LDL; BBR, Berberine; Cur, Curcumin; COX, Cytochrome c oxidase; T2D, Type II diabetes; NAFLD, Non-alcoholic fatty liver disease; CRM, Caloric restriction mimetic.
} 
the cytoplasm); SIRT2 is mainly cytosolic; SIRT3, SIRT4, and SIRT5 are mitochondrial and can shuttle to the nucleus (Chang and Guarente, 2014).

The enzymatic activity of SIRTs is dependent on $\mathrm{NAD}^{+}$as a cofactor and plays an important role in controlling gene expression, DNA repair, metabolism, oxidative stress response, mitochondrial function, and biogenesis. Deregulation of their activity may lead to tissue-specific degenerative events that underlie several human pathologies, including cancer, diabetes, and cardiovascular diseases (Haigis and Sinclair, 2010; O'Callaghan and Vassilopoulos, 2017; Waldman et al., 2018). The most studied member of this enzymatic class is SIRT1. SIRT1 regulates metabolic pathways, cell survival, cellular senescence, and inflammation, and acts in the pathogenesis of chronic conditions such as diabetes as well as pulmonary, neurodegenerative, and cardiovascular diseases. Indeed, SIRT1 has been reported to play a key role in tumorigenesis, as an oncogene or tumor suppressor depending on the context specificity (Biason-Lauber et al., 2013). It is able to control these processes via deacetylation of lysine groups of histone and non-histone proteins, including known transcription factors (FOXO, MyoD, p53, PGC-1 $\alpha$ ) (Kupis et al., 2016).

Chronic inflammation caused by oxidative damage increases the risk of many chronic disorders, including heart, cardiovascular, and neurodegenerative diseases, obesity, insulin resistance, and type 2 diabetes (T2D) (Geto et al., 2020). Oxidative stress plays a key role in the pathogenesis of these conditions. The overproduction of reactive oxygen species (ROS), including free radicals, and reactive nitrogen species (RNS) can lead to damage of cellular components, such as lipids, proteins, and DNA. The imbalance between oxidants and antioxidants can result in cellular dysfunction, apoptosis, and necrosis (Liguori et al., 2018).

SIRT1 guards against oxidative stress by activating gene transcription of PGC-1 $\alpha$ via deacetylation, and by regulating transcription of factors such as the nuclear receptor peroxisome proliferator-activated receptor (PPAR), nuclear respiratory factor (NRF), and mitochondrial transcription factor A (TFAM), involved in modulation of biogenesis and mitochondrial function (Ren et al., 2019), and metabolism of glucose and lipids (Rodgers et al., 2005). SIRT1 is also able to regulate the expression of superoxide dismutase (SOD) and glutathione peroxidase (Sun et al., 2018). In addition, since mitochondrial dysfunction leads to the activation of apoptosis, SIRT1 can directly regulate the apoptotic process by modulating acetylation of PGC- $1 \alpha$ (Zhang et al., 2019). SIRT1 also regulates inflammatory response (Kauppinen et al., 2013). By modulating the acetylation level of NF- $\kappa \mathrm{B}$ p65, SIRT1 is able to control transcription of genes such as IL (interleukin)-1, tumor necrosis factor $\alpha$ (TNF- $\alpha$ ), IL-8, IL-6, and other inflammatory factors (Rodgers et al., 2005; Ren et al., 2019; Yeung et al., 2019). Through NF- $\kappa B$, SIRT1 also regulates the expression of genes such as inhibitor of apoptosis protein (IAP) and B-cell lymphoma-2 (Bcl-2) and tumor necrosis factor receptor (TNFR) (Ren et al., 2019).

SIRT1 protects against oxidative stress via regulation of FOXO protein acetylation, which is involved in antioxidant processes, apoptosis, and cell proliferation (Wong and Woodcock, 2009). By activating FOXO/MsSOD pathway, SIRT1 increases the expression of manganese superoxide dismutase (MnSOD) and catalase, counteracting oxidative stress and promoting damage repair ( $\mathrm{Gu}$ et al., 2016). SIRT1 also increases the expression of MnSOD by deacetylating p53, thus enhancing cellular antioxidant capacity (Brunet et al., 2004; Zhang et al., 2017; Ren et al., 2019).

Over the past few years, the ever-growing awareness that good health goes hand in hand with a healthy and balanced diet has encouraged people to eat more fruit and vegetables, and to take supplements to make up for any deficiency (D'Angelo et al., 2019). Bioactive compounds in the diet can act as antioxidant and anti-inflammatory agents, thereby reducing the negative effects of oxidative stress and the incidence of chronic diseases such as obesity, diabetes, and cardiovascular disorders (Wang et al., 2014). Several molecules, including natural phytochemical compounds, can modulate SIRT1 activity (Miceli et al., 2014). Numerous studies have provided evidence of the protective effects of natural polyphenolic substances such as resveratrol, quercetin, curcumin, and fisetin, and of natural non-polyphenolic substances such as berberine (McCubrey et al., 2017). Natural polyphenols are the largest group of phytonutrients and are considered potential agents for the prevention and treatment of stress-related oxidative diseases. They are found in many plants and foods, such as fruits, vegetables, tea, cereals, and wine, and long-term intake is associated with health benefits. Mediterranean diets are in fact linked to a reduced risk of chronic diseases due to the consumption of olive oil and red wine, which contain high amounts of polyphenols (Romagnolo and Selmin, 2017).

Most of the evidence supporting the beneficial effects of phytochemical compounds comes from in vitro or animal studies, while human studies evaluating the long-term impact of phytomolecules are particularly few or inconsistent. Interventional studies are in fact limited by issues of bioavailability and metabolism. However, in vitro studies aimed at identifying cellular targets linked to the beneficial actions of phytonutrientrich foods at concentrations ranging from $\mathrm{nM}$ to $\mu \mathrm{M}$ challenge the translatability of data. After ingestion, these compounds are in fact detected as phase II metabolites and their blood level does not exceed concentrations in the nM range. Substantial amounts of the compounds and their metabolites are degraded in the colon by intestinal microbiota, giving rise to small phenolic acids and aromatic catabolises which are absorbed by the circulatory system (Del Rio et al., 2013). Interesting studies showed that these natural polyphenol and non-polyphenol substances could affect SIRT1 expression/activity (Table 1) (de Boer et al., 2006). The main mechanisms of action common to polyphenol and nonpolyphenol molecules that lead to antioxidant and antiinflammatory effects via SIRT1 activation are reported in Figure 1.

Here, we focus on the natural molecules resveratrol, quercetin, fisetin, curcumin, and berberine, and elucidate their effect on SIRT1 activation and their potential to treat and/or prevent several human pathologies, mainly associated with metabolic disorders (Figure 2). 
TABLE 1 | Classification of nutraceuticals based on their action and food source.

\begin{tabular}{|c|c|c|c|}
\hline $\begin{array}{l}\text { Natural } \\
\text { SIRT1 } \\
\text { activators }\end{array}$ & Effect & Source & References \\
\hline Resveratrol & $\begin{array}{l}\text { Positive effect on blood } \\
\text { lipid profile, antioxidant }\end{array}$ & $\begin{array}{l}\text { Dark grapes, } \\
\text { raisins, peanuts }\end{array}$ & $\begin{array}{l}\text { D'Angelo (2019) } \\
\text { \#44 } \\
\text { Zordoky (2015) \#54 }\end{array}$ \\
\hline Quercetin & $\begin{array}{l}\text { Anticancer, positive } \\
\text { effect on blood lipid } \\
\text { profile, antioxidant, anti- } \\
\text { inflammatory }\end{array}$ & $\begin{array}{l}\text { Fruits, vegetables, } \\
\text { nuts }\end{array}$ & $\begin{array}{l}\text { Hung (2015) \#72 } \\
\text { Nabavi (2012) \#68 }\end{array}$ \\
\hline Berberine & $\begin{array}{l}\text { Antioxidant, anti- } \\
\text { inflammatory }\end{array}$ & $\begin{array}{l}\text { Natural component } \\
\text { of traditional } \\
\text { Chinese herb } \\
\text { Coptidis rhizoma }\end{array}$ & $\begin{array}{l}\text { Nabavi (2012) \#68 } \\
\text { Wu (2014) \#70 } \\
\text { Hung (2015) \#72 }\end{array}$ \\
\hline Curcumin & $\begin{array}{l}\text { Anticancer, antioxidant, } \\
\text { anti-inflammatory }\end{array}$ & $\begin{array}{l}\text { Active component } \\
\text { in Curcuma longa }\end{array}$ & $\begin{array}{l}\text { Zendedel (2018) } \\
\# 92\end{array}$ \\
\hline Fisetin & $\begin{array}{l}\text { Anticancer, } \\
\text { cardiovascular } \\
\text { preventive, anti- } \\
\text { inflammatory, } \\
\text { antioxidant }\end{array}$ & $\begin{array}{l}\text { Apples, } \\
\text { persimmons, } \\
\text { grapes, onions, } \\
\text { kiwi, kale, } \\
\text { strawberries }\end{array}$ & $\begin{array}{l}\text { Kim (2015) \#98 } \\
\text { Chen et al., 2015) }\end{array}$ \\
\hline
\end{tabular}

\section{NATURAL COMPOUNDS ENHANCING SIRT1 EXPRESSION AND ACTIVITY}

\section{Resveratrol}

Resveratrol (RSV), a non-flavonoid polyphenol found in grapes and grape products such as red wine, exerts an antioxidant action with reported cancer preventive properties (Kris-Etherton et al., 2002). RSV also has anti-inflammatory, anticancer, and anti-neurodegenerative effects (Piotrowska et al., 2012). The role of RSV as an immune response modulator was demonstrated in both in vitro and in vivo studies, where it reversed immune senescence in older rats, reduced inflammatory responses in rodents, and improved immunological activity against cancer cells (Malaguarnera, 2019). RSV was shown to be involved in the activation of macrophages, $T$ cells, and natural killer cells, as well as in the suppression processes of $\mathrm{CD} 4^{+} \mathrm{CD} 25^{+}$regulatory $\mathrm{T}$ cells (Yang et al., 2008; Svajger and Jeras, 2012). All these effects are due to its ability to remove ROS, inhibit cyclooxygenase (COX), and trigger anti-inflammatory pathways via SIRT1 activation (Miceli et al., 2014; Malaguarnera, 2019). Activated SIRT1 interrupts TLR4/NF- $\mathrm{KB} / \mathrm{STAT}$ axis, reduces cytokine production by inactivated immune cells, and inhibits proinflammatory factors derived from macrophages/mast cells, such as platelet-activating factor and TNF- $\alpha$ (Capiralla et al., 2012).

RSV-SIRT1 interaction modifies SIRT1 structure and promotes binding activity with its substrates including p65/ RelA (Yeung et al., 2004), a component of the NF- $\kappa B$ complex, which regulates activation of leukocytes and inflammatory cytokines. SIRT1 activated by RSV inhibits acetylation of RelA by reducing the expression of inflammatory factors such as TNF$\alpha$, IL-1 $\beta$, IL-6, metalloprotease (MMP)-1, MMP-3, and NF$\kappa B$-mediated Cox-2 (Malaguarnera, 2019). AMP activated protein kinase (AMPK) is also a target of RSV, as it controls SIRT1 activity via regulation of cellular levels of $\mathrm{NAD}^{+}$, thus acting as an energy sensor (Price et al., 2012). Cyclic adenosine monophosphate (cAMP) levels activate protein kinase A, resulting in phosphorylation and activation of SIRT1

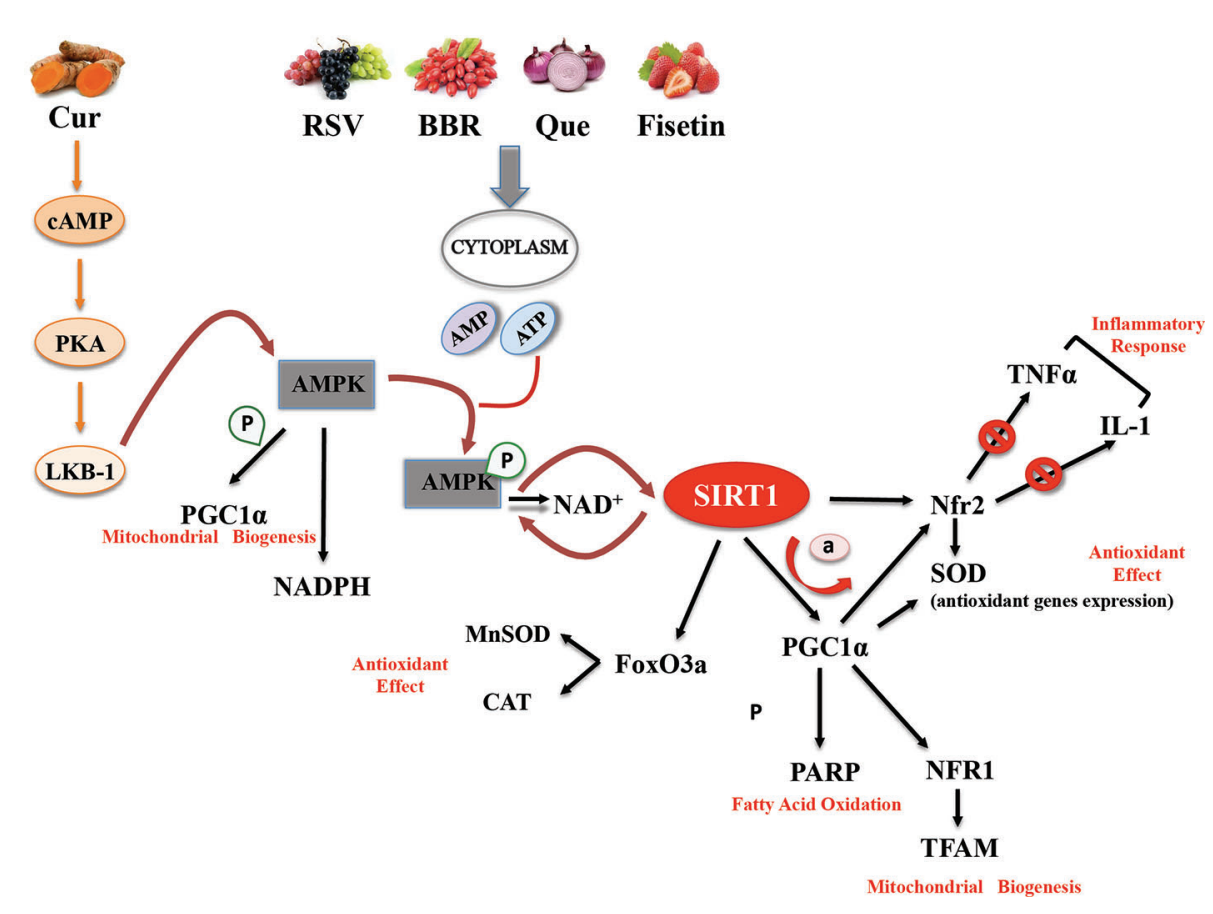

FIGURE 1 | Basic mechanisms and effects of SIRT1 activation by polyphenol and non-polyphenol molecules. 


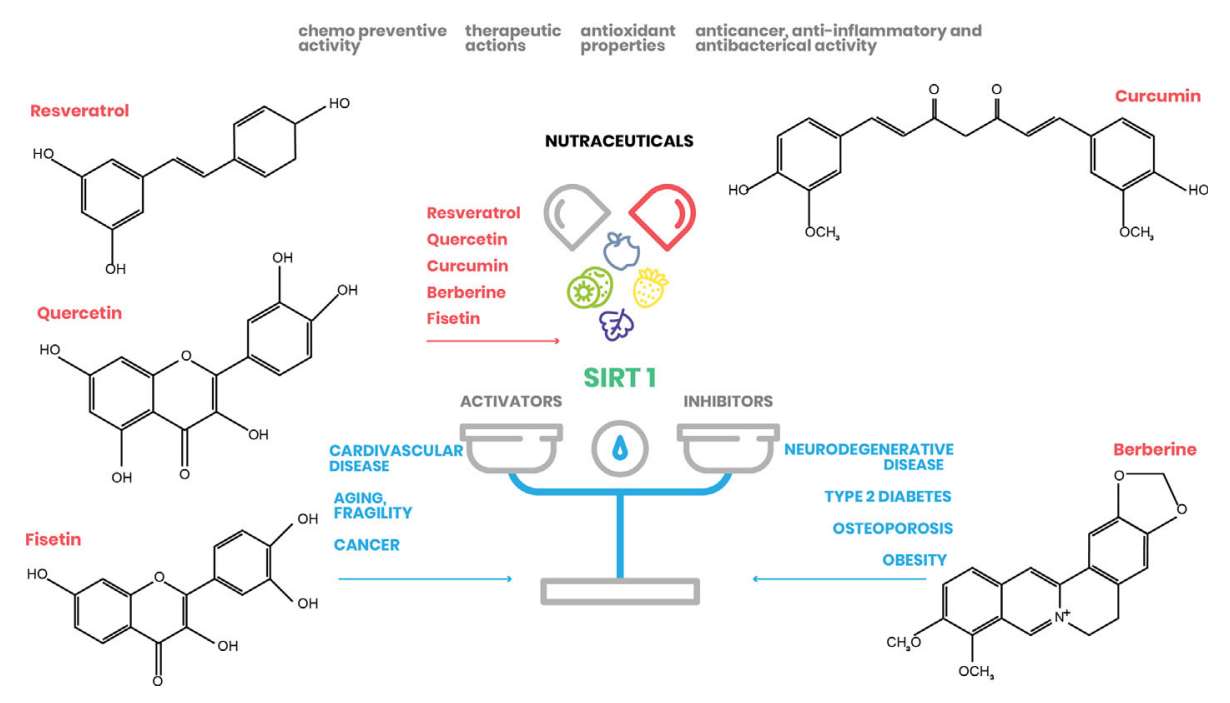

FIGURE 2 | Nutraceutical action on SIRT1 expression. Natural substances have beneficial effects on human health by regulating SIRT1 action in different cellular processes (www.pubchem.ncbi.nlm.nih.gov).

(Wan et al., 2016). Activated SIRT1 catalyzes the deacetylation and activation of PGC-1 $\alpha$, thereby promoting beneficial effects in the metabolism (Ren et al., 2019).

In different organisms (S. cerevisiae, C. elegans, and D. melanogaster) expressing SIRT1 (or its homologous genes), RSV treatment is able to extend life span. In mammalians, RSV administration can improve SIRT1-dependent cellular processes such as axonal protection (Araki et al., 2004), fat mobilization (Chaplin et al., 2018), and inhibition of NF- $\mathrm{KB}-$ dependent transcription (Yeung et al., 2019); these effects are abolished in SIRT1 knockdown models. Numerous studies investigated the beneficial effects of RSV in cardiovascular diseases including hypertension (Theodotou et al., 2017), cardiac ischemia (Fourny et al., 2019), and atherosclerosis (Chassot et al., 2018). RSV has an effect on blood vessels, reduces inflammation, and prevents thrombus formation and platelet oxidation (Zordoky et al., 2015). It can also reduce cardiac dysfunction, oxidative stress, fibrosis, and apoptosis in the heart (Gupta et al., 2014; Yamagata, 2019). In addition, RSV was found to improve heart and kidney damage in rats (Li et al., 2020a). The protective effect of RSV is associated with an increase in SIRT1 activity, which deacetylates FOXO1 and activates MnSOD downstream. RSV-induced MnSOD also reduces oxidative stress ( $\mathrm{Li}$ et al., 2020a). A recent in vitro study showed that RSV reduces hypoxia-induced apoptosis in H9C2 cells through activation of SIRT1/miR-30d-5p/NF- $\kappa$ B axis (Han et al., 2020). RSV treatment decreased cortical and hippocampal malondialdehyde levels while increasing SOD activity and SIRT1 expression in a diabetic rat model (Ma et al., 2019).

RSV was shown to activate SIRT1 and improve endothelial function in obese mice via upregulation of PPAR $\delta$ expression/ activity in PPAR $\delta$ mutant mice (Cheang et al., 2019). It had previously been observed that Akt activation together with PPAR $\delta$ is involved in vascularization of $\mathrm{db} / \mathrm{db}$ mice (Tian et al., 2012); RSV was subsequently reported to increase phosphorylation of Akt and transcriptional activity of PPAR $\delta$ in the aorta of wild-type mice, thus supporting the hypothesis of SIRT1-PPAR $\delta$ interaction, and to strongly decrease LPCinduced mitochondrial ROS in the aortic endothelium of C57BL/6 mice (Cheang et al., 2019). Taken together, these findings highlight the beneficial effects of RSV against oxidative stress, which is involved in major pathologies such as heart and metabolic disorders. Although RSV is beneficial in many contexts, its pleiotropic actions need to be better studied in order to understand which of its described activities are directly due to SIRT1 modulation and whether this effect is always direct.

Because of the pleiotropic actions of RSV, clinical trials are currently testing its therapeutic potential in a wide range of human diseases. However, of all the mechanisms described in in vitro and in vivo studies, only a few have been confirmed in humans, such as gene and protein regulation in blood or muscle cells, and Akt signaling pathways (Ghanim et al., 2010; Brasnyo et al., 2011). Many clinical studies conducted in healthy patients and volunteers using both high and low doses of RSV highlight its potential cardioprotective benefit through improvement of endothelial function, inflammatory markers, and glucose metabolism. Nevertheless, the mechanisms of action are not yet well defined. Despite clinical evidence of its effects, the poor bioavailability and rapid metabolism of RSV severely limit the potential use of this molecule in the clinic. Future scientific research should focus on identifying actual metabolites or mediators of these observed effects.

To date, 165 clinical trials have tested the efficacy, safety, and pharmacokinetics of RSV in the prevention and treatment of 32 different pathological conditions (www.clinical.trials.gov). 
Restricting the search to interventional phase $1 / 2 / 3 / 4$ studies (completed and terminated clinical trials), 55 addressed the ability of RSV to improve the pathological conditions of patients affected by several diseases. Most of these studies tested RSV-mediated effects in central nervous system disorders (Friedreich ataxia, Alzheimer's disease, Parkinson's disease), metabolic disorders [T2D, insulin resistance, dyslipidemia, hypercholesterolemia, metabolic syndrome $\mathrm{X}$, non-alcoholic fatty liver disease (NAFLD)]. A phase 1 clinical trial (NCT01640197) tested the effects of chronic resveratrol supplementation (500 mg daily for 28 days) in healthy humans and found considerable improvements in cognitive performance, cerebral blood flow, subjective sleep, mood, health, and blood pressure. A list of completed and terminated clinical trials in which RSV was tested for metabolic disorders is reported in Table 2. Focusing on completed clinical trials with available results, NCT02114892 evaluated the effect of RSV on metabolic syndrome, demonstrating that, when administered three times per day $(1,500 \mathrm{mg} / \mathrm{die})$ before meals, RSV was able to treat and protect from obesity and diabetes with beneficial effects on glucose and lipid metabolism, blood pressure, and body weight. Another phase 1/2 study (NCT02095873) evaluated the effects of a formulation composed of RSV and hesperetin in obese subjects and found that these molecules are dietary inducers of glyxalase 1, improving metabolic and vascular health of obese subjects (Xue et al., 2016).

\section{Quercetin}

The flavonoid polyphenol quercetin (Que; 3,3', $4^{\prime}, 5,7$ pentahydroxyflavone) is a natural, safe dietary supplement found in a glycoside form in fruits, vegetables, and nuts, which has antioxidant and anti-inflammatory properties (Nabavi et al., 2012; Wu et al., 2014).

In recent years, the scientific community has focused on the potential antiproliferative, chemopreventive and anticarcinogenic activities of Que as well as on its role as a modulator of gene expression. However, Que was also found to have potentially toxic effects including mutagenicity, pro-oxidant activity, mitochondrial toxicity, and inhibition of enzymes involved in hormonal metabolism (Li et al., 2016). Due to its poor solubility, short halflife, and low bioavailability, its medical use is limited (Konrad and Nieman, 2015). In humans, Que bioavailability is very low ( 2\%) and absorption varies from $3 \%$ to $17 \%$ in subjects receiving $100 \mathrm{mg} /$ die (Costa et al., 2016). Que may reduce infection (Li et al., 2016), hepatic lipemic-oxidative damage (Cui et al., 2013) (Zhang et al., 2016b), and antioxidant risk (Xu et al., 2019). In addition, Que is known to exert a modulating action on immunity (Galleggiante et al., 2019). As regards its mechanism of action, in some cell lines Que was able to inhibit the production of TNF in macrophages (Tang et al., 2019), IL-8 in A549 lung cells induced by lipopolysaccharide (LPS) (Geraets et al., 2007), and TNF- $\alpha$ and IL- $1 \alpha$ mRNA levels in glial cells, causing a decrease in neuronal cell death induced by microglial activation (Li et al., 2016). Mainly

TABLE 2 | Resveratrol in clinical trials for metabolic disorders.

\begin{tabular}{|c|c|c|c|c|c|}
\hline Status & Study Title & Conditions & Intervention & Phase & NCT Number \\
\hline Completed & $\begin{array}{l}\text { Effects of Resveratrol in Patients With Type } \\
2 \text { Diabetes }\end{array}$ & Type 2 Diabetes & $\begin{array}{l}500 \text { mg to a maximum dose of } \\
3 \mathrm{~g} \text { daily }\end{array}$ & Phase 1 & NCT01677611 \\
\hline Terminated & $\begin{array}{l}\text { Effect of Administration of Resveratrol on } \\
\text { Glycemic Variability in Individuals With Type } \\
2 \text { Diabetes Mellitus }\end{array}$ & Type 2 Diabetes Mellitus & 500 mg 3 times daily & Phase 2 & NCT02549924 \\
\hline Completed & $\begin{array}{l}\text { Effect of Resveratrol on Age-related Insulin } \\
\text { Resistance and Inflammation in Humans }\end{array}$ & $\begin{array}{l}\text { Type } 2 \text { Diabetes Mellitus \& Insulin } \\
\text { Resistance }\end{array}$ & 1,000 mg twice daily for 28 days & Phase 2 & NCT01354977 \\
\hline Completed & $\begin{array}{l}\text { Regulation of Intestinal and Hepatic } \\
\text { Lipoprotein Secretion by Resveratrol }\end{array}$ & Dyslipidaemia \& Insulin Resistance & $\begin{array}{l}500 \mathrm{mg} \text { for } 1 \text { week followed by } \\
1 \mathrm{~g} \text { for } 1 \text { week }\end{array}$ & Phase 2 & NCT01451918 \\
\hline Completed & $\begin{array}{l}\text { Effects of Dietary Antioxidants to Prevent } \\
\text { Cardiovascular Disease }\end{array}$ & Hypercholesterolemia \& Healthy & $\begin{array}{l}\text { Dietary Supplement: red wine for } \\
1 \text { month } \\
\text { Dietary Supplement: } \\
\text { resveratrol for } 1 \text { month }\end{array}$ & Phase 2 & NCT02409537 \\
\hline $\begin{array}{l}\text { Completed } \\
\text { with results }\end{array}$ & Healthy Aging Through Functional Food & $\begin{array}{l}\text { Glucose Intolerance \& Aortic Stiffness \& } \\
\text { Vasodilation }\end{array}$ & $\begin{array}{l}\text { Trans-resveratrol, } 90 \text { mg + } \\
\text { hesperetin, } 120 \text { mg (combination) }\end{array}$ & Phase 1/2 & NCT02095873 \\
\hline Completed & $\begin{array}{l}\text { Effects of Resveratrol on Inflammation in } \\
\text { Type } 2 \text { Diabetic Patients }\end{array}$ & $\begin{array}{l}\text { Type } 2 \text { Diabetes Mellitus \& Inflammation \& } \\
\text { Insulin Resistance \& Other Disorders of } \\
\text { Bone Density and Structure }\end{array}$ & $\begin{array}{l}6 \text { months } 40 \text { mg daily then } 6 \\
\text { months } 500 \text { mg daily }\end{array}$ & Phase 3 & NCT02244879 \\
\hline $\begin{array}{l}\text { Completed } \\
\text { with results }\end{array}$ & $\begin{array}{l}\text { Effect of Resveratrol Administration on } \\
\text { Metabolic Syndrome, Insulin Sensitivity and } \\
\text { Insulin Secretion }\end{array}$ & Metabolic Syndrome X & $\begin{array}{l}500 \text { mg } 3 \text { times daily before } \\
\text { meals with a total dose of } 1,500 \\
\text { mg daily }\end{array}$ & Phase 2 & NCT02114892 \\
\hline Completed & $\begin{array}{l}\text { Resveratrol for the Treatment of Non } \\
\text { Alcoholic Fatty Liver Disease and Insulin } \\
\text { Resistance in Overweight Adolescents }\end{array}$ & $\begin{array}{l}\text { NAFLD \& Type } 2 \text { Diabetes \& Metabolic } \\
\text { Syndrome }\end{array}$ & $\begin{array}{l}75 \mathrm{mg} \text { twice daily for a total daily } \\
\text { dose of } 150 \mathrm{mg} \text { for } 30 \text { days }\end{array}$ & Phase 2/3 & NCT02216552 \\
\hline Completed & $\begin{array}{l}\text { A Study of Resveratrol as Treatment for } \\
\text { Friedreich Ataxia }\end{array}$ & Friedreich Ataxia & $\begin{array}{l}1 \mathrm{~g} \text { daily ( } 500 \mathrm{mg} \text { twice daily) for } \\
12 \text { weeks then } 5 \mathrm{~g} \text { daily ( } 2.5 \mathrm{~g} \\
\text { twice daily) for } 12 \text { weeks }\end{array}$ & Phase $1 / 2$ & NCT01339884 \\
\hline Completed & $\begin{array}{l}\text { Effect of Banaba (Lagerstroemia Speciosa) } \\
\text { on Metabolic Syndrome, Insulin Secretion } \\
\text { and Insulin Sensitivity }\end{array}$ & Metabolic Syndrome X & $\begin{array}{l}\text { Banaba capsules, } 500 \text { mg, } 2 \\
\text { times daily before meals for } 90 \\
\text { days }\end{array}$ & Phase 2 & NCT02767869 \\
\hline
\end{tabular}


in immunity and inflammation, Que acts on leukocytes and targets many intracellular signaling kinases and phosphatases as well as enzymes and membrane proteins (Li et al., 2016). The immunostimulating effect of Que is due to induction of the expression of interferon- $\gamma($ IFN- $\gamma$ ) derived from Th- 1 and inhibition of IL-4 derived from Th-2 in normal peripheral blood mononuclear cells (Nair et al., 2002). In addition, Que reduces T cell proliferation by blocking IL-12-induced tyrosine phosphorylation of JAK2, TYK2, STAT3, and STAT4 (Muthian and Bright, 2004; Nabavi et al., 2012). In inflammation, Que inhibits the enzymes COX and lipoxygenase (Lee and Min, 2013; Savikin et al., 2017). In the RAW 264.7 cell line, Que was also shown to counteract LPSinduced inflammation by phosphorylation of tyrosine phosphatidylinositol-3-kinase (PI3K)-p85 and complex formation of toll-like receptor 4 (TLR4)/MyD88/PI3K (Endale et al., 2013).

Oxidative stress occurs following an imbalance of the body's antioxidant defence mechanisms and excessive generation of free radicals, and is involved in various pathologies such as diabetes, atherosclerosis, hypertension, neurodegenerative diseases, inflammation, and cancer (Oboh et al., 2016). Que is a powerful ROS scavenger and its antioxidant action is due to the presence of two pharmacophores within the molecular structure, which confer a favorable configuration for free radical elimination (Costa et al., 2016). Generally, Que reduces the effects of free radicals by transferring the hydrogen atom and stabilizing the radicals, a feature that has a structure-function relationship (Oboh et al., 2016).

Que can also act as both an antioxidant and pro-oxidant agent. At low concentrations $(10-10 \mu \mathrm{M})$, Que displayed a protective effect against oxidative DNA damage (in vitro) in human lymphocytes ( $\mathrm{Li}$ et al., 2016). At concentrations between $5 \mu \mathrm{M}$ and $50 \mu \mathrm{M}$, Que was able to directly eliminate ROS in vitro (Costa et al., 2016). However, its effect in vivo is very likely not direct but due to its ability to modulate the cell's antioxidant defense mechanisms; moderate oxidative stress can in fact increase the cell's antioxidant defenses, resulting in general cytoprotection (Halliwell et al., 2005). Recent research showed that oxidized LDL (oxLDL) induces oxidative stress (Lara-Guzman et al., 2018). Oxidative injuries promote ROS generation in human endothelial cells and SIRT1 regulates endothelial function. Therefore, enhancement of SIRT1 activity and SIRT1/AMPK axis upregulation inhibits oxidative injury, inducing endothelial dysfunction (Chen et al., 2013) (Shentu et al., 2016). Que may reduce oxLDL-induced oxidative damage by upregulating SIRT1 and AMPK (Hung et al., 2015), therefore potentially preventing oxLDL-impaired SIRT1 inhibition linked to endothelial dysfunction. These findings indicate that SIRT1 can function as a regulator to improve AMPK activity under oxLDL stimulation (Hung et al., 2015).

It was very recently shown that Que $(70 \mathrm{mg} / \mathrm{kg})$ can reduce insulin resistance and improve glucose metabolism by reducing sensitivity to $\mathrm{T} 2 \mathrm{D} /$ insulin resistance in ob/ob mice via SIRT1 activation (Hu et al., 2020). In this context, another study showed that in streptozotocin-induced diabetic rats, Que $(100 \mathrm{mg} / \mathrm{kg})$ inhibits oxidative damage by increasing SIRT1 expression and decreasing levels of NF- $\kappa B$, a SIRT1 substrate (Iskender et al., 2017).
In recent years, the scientific community has focused on the role of apoptosis in cardiovascular disease, showing that oxidative stress, myocardial ischemia, hypoxia, and ischemia/ reperfusion injury may induce myocardial apoptosis (Donniacuo et al., 2019). Tang and colleagues evaluated the effects of Que in improving myocardial ischemia/reperfusion injury (MI/R)induced cell apoptosis both in vitro and in vivo. SIRT1 and PGC-1 $\alpha$ expression levels were decreased in rat MI/R groups, but were significantly increased after treatment with Que (Tang et al., 2019). Furthermore, activation of SIRT1/PGC- $1 \alpha$ pathway upregulated Bcl-2 expression and downregulated Bax, exerting anti-apoptotic effects. The authors hypothesized that Que might improve $\mathrm{MI} / \mathrm{R}$-induced myocardial damage via regulation of SIRT1/PGC-1 $\alpha$ and Bcl-2/Bax pathways (Tang et al., 2019). Que is also reported to regulate ROS generation and mitigate mitochondrial dysfunction by promoting their biogenesis. Specifically, in a study to develop a therapeutic strategy for osteoarthritis, Que was shown to increase expression levels of SIRT1, PGC-1 $\alpha$, NRF1 and NFR2, TFAM, and phospho-AMPK $\alpha$ in osteoarthritis rats, confirming the hypothesis that Que might act via the AMPK/SIRT1 signaling pathway (Qiu et al., 2018). Overall, these findings suggest that Que may counteract cardiovascular disease and oxidative damage.

The growing body of evidence supporting the beneficial effects of Que has led to its clinical use, as demonstrated by the number of clinical trials (72 studies on ClinicalTrials.gov). A list of completed studies using Que in different metabolic and inflammatory conditions is reported in Table 3. Specifically, a phase 2 clinical trial (NCT01839344) measured the effect of Que on glucose tolerance and postprandial endothelial function in subjects with T2D compared to the effect of an alpha-glusidase inhibitor, acarbose. The administration of $2 \mathrm{~g}$ of Que led to a decrease in postprandial blood glucose (NCT01839344). Given its antioxidative and antiinflammatory capacities, this flavonoid was considered a good candidate for antioxidant therapy in mucositis (NCT01732393), hepatitis C (NCT01438320), idiopathic pulmonary fibrosis (NCT02874989), osteoporosis (NCT00330096), uric acid metabolism (NCT01881919), cytokine release (NCT01106170), and chronic obstructive pulmonary disease (NCT01708278). In the latter study, Que supplementation was safely tolerated by patients with mild-to-severe chronic obstructive pulmonary disease, opening the way towards the potential use of Que as a therapeutic agent for this condition.

However, as for RSV and nutraceuticals in general, the results of molecular studies on Que obtained from in vitro investigations and animal models are often inconsistent with data from clinical trials. Concentration factor (dose and timing of administration) and bioavailability are the two main issues that require further clarification. Additional studies are needed to identify the optimal concentration of Que for it to exert a beneficial effect, for example on insulin sensitivity.

\section{Berberine}

Berberine (BBR) is an isoquinoline alkaloid reported to have analgesic, anticancer, anti-inflammatory, and myocardial protective properties (Cicero and Baggioni, 2016). It was found 
TABLE 3 | Quercetin in clinical trials for metabolic and inflammatory disorders.

\begin{tabular}{|c|c|c|c|c|c|}
\hline Status & Study Title & Conditions & Intervention & Phase & NCT Number \\
\hline Completed & $\begin{array}{l}\text { Effect of Quercetin in Prevention and } \\
\text { Treatment of Oral Mucositis }\end{array}$ & $\begin{array}{l}\text { Chemotherapy Induced Oral } \\
\text { Mucositis }\end{array}$ & 250 mg daily for 3 weeks & Phase $1 / 2$ & NCT01732393 \\
\hline Completed & Beneficial Effects of Quercetin in Chronic & Chronic Obstructive & 500 to $2,000 \mathrm{mg}$ daily for 1 week & Phase 1 & NCT01708278 \\
\hline with results & Obstructive Pulmonary Disease (COPD) & Pulmonary Disease & & & \\
\hline Completed & Q-Trial in Patients With Hepatitis C & Chronic Hepatitis C & 28 days & Phase 1 & NCT01438320 \\
\hline Completed & $\begin{array}{l}\text { Effects of Quercetin on Blood Sugar and } \\
\text { Blood Vessel Function in Type } 2 \\
\text { Diabetes. }\end{array}$ & Diabetes Mellitus, Type 2 & $250 \mathrm{mg}$; oral single dose of $2000 \mathrm{mg}$ & Phase 2 & NCT01839344 \\
\hline Completed & $\begin{array}{l}\text { Effect of Quercetin Supplements on } \\
\text { Healthy Males: a 4-Week Randomized } \\
\text { Cross-Over Trial }\end{array}$ & $\begin{array}{l}\text { Hyperuricemia, Gout, Kidney } \\
\text { Calculi, Diabetes, } \\
\text { Cardiovascular Disease }\end{array}$ & $\begin{array}{l}500 \text { mg tablet for } 28 \text { days with meal (breakfast } \\
\text { preferred.) }\end{array}$ & $\begin{array}{l}\text { Early Phase } \\
1\end{array}$ & NCT01881919 \\
\hline Completed & $\begin{array}{l}\text { Targeting Pro-Inflammatory Cells in } \\
\text { Idiopathic Pulmonary Fibrosis: a Human } \\
\text { Trial }\end{array}$ & $\begin{array}{l}\text { Idiopathic Pulmonary Fibrosis } \\
\text { (IPF) }\end{array}$ & $\begin{array}{l}3 \text { doses administered over } 3 \text { consecutive days in } \\
3 \text { consecutive weeks, oral administration of } \\
\text { quercetin ( } 1,250 \mathrm{mg} \text { daily) }\end{array}$ & Phase 1 & NCT02874989 \\
\hline Completed & $\begin{array}{l}\text { Efficacy of Provex CV Supplement to } \\
\text { Reduce Inflammation Cytokines and } \\
\text { Blood Pressure }\end{array}$ & Blood Pressure & $\begin{array}{l}330 \text { mg of Provex CV supplement, by mouth, per } \\
\text { day, for } 4 \text { weeks }\end{array}$ & Phase 1 & NCT01106170 \\
\hline Completed & $\begin{array}{l}\text { Effects of Hesperidin on Bone Mineral } \\
\text { Density and Bone Metabolism of } \\
\text { Postmenopausal Women }\end{array}$ & Osteoporosis, Osteopenia & & Phase 3 & NCT00330096 \\
\hline
\end{tabular}

to exert protective antioxidative effects in different physiologic and pathologic conditions (Huang et al., 2018; Li et al., 2020b). However, the mechanisms underlying these effects remain unclear. BBR was described as a potential antitumor agent that induces cell cycle arrest in G0/G1 phase, increases Cip/p21 and Kip/p27 protein expression, decreases expression of cyclin D1, $\mathrm{D} 2$, and DE, and the cyclin-dependent kinases Cdk2, Cdk4, and Cdk6, promoting apoptosis in HL-60 human leukemia cells (Li et al., 2017). BBR can also deregulate telomerase activity and promote mitochondria-dependent apoptosis in HepG2 human hepatocarcinoma cells through caspase 8 and caspase 3 activation, PARP cleavage induction, increased expression of the pro-apoptotic protein Bax through activation of FOXO transcription factors, and inhibition of $\mathrm{Bcl}-2$ and $\mathrm{Bcl}-\mathrm{x}$ antiapoptotic protein expression (Hwang et al., 2006). BBR was observed to exert an apoptotic effect by inducing ROS production and increasing MAPK and JNK activity of p38 in SW620 human colon carcinoma cells, and by increasing $\mathrm{Ca}^{+}$and cytochrome C release in HSC-3 squamous cells (Song et al., 2020). In addition, BBR inhibits the proliferation of cancer cells through an anti-inflammatory pathway. In oral carcinoma cell lines and in SCC-4 cells, BBR inhibits expression of COX2 and AP-1 bond, decreases prostaglandin E2 (PGE2) production, and suppresses NF- KB, IKK, ERK, and JNK activities. Furthermore, $\mathrm{BBR}$ can inhibit colon cancer cell growth by activating retinoid $\mathrm{X}$ receptor $\alpha(\mathrm{RXR} \alpha)$, which binds $\mathrm{RXR} \alpha$, and promoting $\beta$ catenin degradation (Ruan et al., 2017). However, some studies highlighted the potential ability of BBR to prevent oxidative stress-induced senescence by activating AMPK and restoring $\mathrm{NAD}^{+}$levels (Song et al., 2020).

Initial research revealed a significant role of SIRT1 signaling in mediating the antioxidant effect of BBR in diabetes (Pang et al., 2015) and in lipid metabolism (Hasanein et al., 2017). The lipid-lowering activity mediated by co-treatment with BBR and RSV was investigated in mice exposed to a high fat diet (Zhu et al., 2018). In vivo data showed that BBR combined with RSV lowered total cholesterol, triglyceride, and LDL cholesterol levels in mice. These findings were also confirmed in vitro with 3T3-L1 adipocytes treated with BBR or RSV alone. Specifically, BBR and RSV co-treatment was able to reduce lipid accumulation more robustly than single treatments. BBR in combination with RSV displayed hypolipidemic effects likely mediated by SIRT1 expression regulation. Moreover, BBR pre-treatment seemed to counteract SIRT1 downregulation (Zhu et al., 2018).

The antioxidant and anti-inflammatory effects of BBR were also investigated in heart (Yu et al., 2016). BBR-mediated SIRT1 activation reduced $\mathrm{MI} / \mathrm{R}$ injury by affecting oxidative damage and inflammation signaling. Specifically, BBR exerted an antioxidant effect by decreasing the generation of cardiac superoxide and gp91 ${ }^{\text {phox }}$ expression, and by increasing SOD levels (Yu et al., 2016). A previous study had also shown that SIRT1 activation promotes antioxidant molecule production and decreases pro-apoptotic proteins through FOXO1 activation, thus protecting against MI/R lesions (Hsu et al., 2010).

As well as activating SIRT1, BBR is also able to decrease FOXO1 acetylation, triggering anti-apoptotic signaling pathways via $\mathrm{Bcl}-2$ expression, and Bax and caspase-3 downregulation ( $\mathrm{Yu}$ et al., 2016).

A very recent report described the protective effect of BBR against doxorubicin-induced cardiovascular damage (Wu et al., 2019). This effect is mediated by SIRT $1 /$ p66Shc pathway (Sampaio et al., 2016). Data obtained in a rat model and in rat H9c2 cardiac cells showed that BBR treatment leads to upregulation of SIRT1 and downregulation of p66shc expression both in vivo and in vitro, resulting in suppression of ROS production, apoptosis, and mitochondrial damage, and improving cardiac dysfunction. This effect did not occur if H9c2 cells were treated with the SIRT1 inhibitor EX-527 (Bai et al., 2018), indicating that BBR action was dependent on SIRT1 (Wu et al., 2019). Another study investigated the beneficial effect of BBR in an in vivo diabetic mouse model and 
in vitro pancreatic beta cell NIT-1 high glucose treated to induced diabetic condition. BBR attenuated oxidative stress by increasing SOD1 levels through activation of SIRT1 and inhibition of miR106b expression (Chen and Yang, 2017).

These promising results have paved the way towards the clinical use of BBR. A list of clinical studies investigating the beneficial effects of BBR in inflammatory and metabolic diseases is reported in Table 4. Given the experimental efficacy of the antidiabetic and antidyslipidemia action of BBR, most of the 18 completed or terminated clinical trials focused on these properties. Two clinical trials tested the anti-diabetic effect of BBR in patients with diabetes or diabetes and dyslipidemia (NCT00425009 and NCT00462046). Several clinical studies investigated its effects on hyperlipidemia and hypercholesterolemia and relative disorders. In particular, two phase 4 clinical trials (NCT02422927 and NCT03470376) tested the ability of a nutraceutical combination containing $500 \mathrm{mg}$ BBR to ameliorate inflammation lipid profile and endothelial injury markers in patients with elevated levels of high-sensitivity C-reactive protein and in HIV-infected patients receiving stable antiretroviral therapy. In addition, a phase 2 clinical study (NCT03216811) assessed the efficacy of a nutraceutical compound ( $3 \mathrm{mg}$ containing fermented red rice) in terms of cholesterol, and endothelial and inflammatory parameters in subjects with hypercholesterolemia and low-tomoderate cardiovascular risk. The findings of a very recent study suggest that BBR may be effective and safe to reduce cardiovascular risk associated with metabolic syndrome (Mercurio et al., 2020).

\section{Curcumin}

Curcumin (Cur) or 1,7-bis(4-hydroxy-3-methoxyphenyl)-1,6heptadiene-3,5-dione (diferuloylmethane) is a natural bioactive polyphenol compound mediating a wide spectrum of biological functions. The molecular structure of Cur consists of two aromatic rings containing phenolic $\mathrm{O}$-methoxy groups linked by a carbon bond, which has a $\beta$-unsaturated $\beta$-diketone fraction (Priyadarsini, 2014). Thousands of years ago, Indians and Chinese described the health-giving effects of this substance, derived from the turmeric plant (Gupta et al., 2014). Today, Cur is considered a potential agent with antioxidant, anticancer, and anti-inflammatory properties (Yu et al., 2019).

As an antioxidant, Cur is able to eliminate ROS and RNS by increasing the expression of antioxidant proteins via induction of upstream coding genes such as nuclear factor erythroid 2related factor 2 (Nrf2), kelch-like ECH-associated protein 1 (Keap1), and antioxidant response element (ARE) (Abdelsamia et al., 2019). Nrf2 is a transcription factor involved in cellular stress response. Under normal conditions, the cystine-rich zinc Keap1 metalloprotein binds Nrf2 inside the cytoplasm, promoting ubiquitination and consequent proteasomal degradation and preventing Nrf2 nuclear translocation (Serafini et al., 2019). In contrast, under stress conditions Keap1 activity is inhibited by phosphorylation and free Nrf2 moves to the nucleus, where it binds to ARE in the regulatory regions of cytoprotective proteins and promotes transcription of antioxidant genes such as SOD, glutathione peroxidase (GPx), and GSH, and of phase II detoxifying enzymes such as heme oxygenase-1 (HO-1), glutathione transferases (GST), nicotinamide adenine dinucleotide phosphate (NADPH), and $\mathrm{NAD}(\mathrm{P}) \mathrm{H}$ dehydrogenase [quinone] 1 (NQO1) (Serafini et al., 2019). Cur is able to activate Nrf2/Keap1/ARE signaling pathway by Michael reaction with thiol residues in Keap1, inducing the release and activation of Nrf2 and promoting antioxidant effects (Wafi et al., 2019; Yu et al., 2019).

TABLE 4 | Berberine in clinical trials for metabolic and inflammatory disorders.

\begin{tabular}{|c|c|c|c|c|c|}
\hline Status & Study Title & Conditions & Intervention & Phase & NCT Number \\
\hline Completed & Therapeutic Effects of Berberine in Patients With Type 2 Diabetes & Type 2 Diabetes & & Phase $1 / 2$ & NCT00425009 \\
\hline Completed & $\begin{array}{l}\text { Efficacy and Safety of Berberine in the Treatment of Diabetes With } \\
\text { Dyslipidemia }\end{array}$ & $\begin{array}{l}\text { Diabetes Mellitus, Type } \\
\text { 2, Metabolic Syndrome }\end{array}$ & $1 \mathrm{~g}$ daily & Phase 3 & NCT00462046 \\
\hline Terminated & The Therapeutic Effects of Statins and Berberine on the Hyperlipemia & Dyslipidemias & $\begin{array}{l}500 \text { mg twice daily for } \\
8 \text { weeks }\end{array}$ & Phase 4 & NCT01697735 \\
\hline Completed & $\begin{array}{l}\text { Efficacy and Tolerability of the Nutraceutical Formulation Coleosoma in } \\
\text { Dyslipidemic Subjects (Coleosoma) }\end{array}$ & Dyslipidemias & $\begin{array}{l}\text { Coleosoma } 500 \mathrm{mg} \\
\text { daily for } 12 \text { weeks }\end{array}$ & Phase 2 & NCT03027336 \\
\hline Completed & $\begin{array}{l}\text { Combined Effects of Bioactive Compounds in Lipid Profile (ARM-PLUS- } \\
\text { LDL) }\end{array}$ & $\begin{array}{l}\text { Hyperlipidemia, Low- } \\
\text { density-lipoprotein- } \\
\text { type, Elevated } \\
\text { Triglycerides }\end{array}$ & $\begin{array}{l}\text { One tablet per day } \\
\text { during } 12 \text { weeks }\end{array}$ & Phase 2/3 & NCT01562080 \\
\hline Completed & $\begin{array}{l}\text { Long Term Efficacy and Tolerability of a Nutraceutical Combination (Red } \\
\text { Yeast Rice, Policosanols and Berberine) in Low-moderate Risk } \\
\text { Hypercholesterolemic Patients: a Double-blind, Placebo Controlled Study }\end{array}$ & Hypercholesterolemia & $\begin{array}{l}500 \text { mg daily for } 24 \\
\text { weeks }\end{array}$ & Phase 4 & NCT02078167 \\
\hline Completed & $\begin{array}{l}\text { NUtraceutical TReatment for hYpercholesterolemia in HIV-infected } \\
\text { Patients (NU-TRY(HIV)) }\end{array}$ & $\begin{array}{l}\text { Hypercholesterolemia } \\
\text { Inflammation } \\
\text { Atherosclerosis }\end{array}$ & $\begin{array}{l}500 \text { mg daily for } 3 \\
\text { months }\end{array}$ & Phase 4 & NCT03470376 \\
\hline Completed & $\begin{array}{l}\text { Nutraceutical Combination in Patients With Low-grade Systemic } \\
\text { Inflammation }\end{array}$ & $\begin{array}{l}\text { Hypercholesterolemia } \\
\text { Inflammation } \\
\text { Atherosclerosis }\end{array}$ & $500 \mathrm{mg}$ for 3 months & Phase 4 & NCT02422927 \\
\hline Completed & Nutraceutical in Cardiovascular Primary Prevention (NIRVANA) & Hypercholesterolemia & $\begin{array}{l}\text { 8-week administration } \\
\text { of nutraceutical } \\
\text { compound } \\
3 \mathrm{mg}\end{array}$ & Phase 2 & NCT03216811 \\
\hline
\end{tabular}


Cur was also shown to exert immunomodulatory activity by interacting with elements involved in inflammatory response including JAK/STAT pathway, suppressor of cytokine signaling (SOCS) expression, and TLR4/MyD88/NF- $\mathrm{KB}$ axis. Cur inhibits phosphorylation of JAK/STAT by binding with its $\alpha, \beta$ unsaturated carbonyl portion to residue 259 of cysteine in STAT3 with subsequent activation. It is known that in vitro, even at $7.5 \mu \mathrm{M}$ concentration, Cur is able to phosphorylate STAT3 and attenuate inflammatory response (Serafini et al., 2019). SOCS is an antagonist of JAK/STAT signaling and is involved in the regulation of inflammatory proteins and cytokines. In vitro, Cur restores expression of SOCS1 and SOCS3, and inhibits expression of IL-6, TNF- $\alpha$, and PGE2 in RAW 264.7 macrophages (Guimaraes et al., 2013), while in vivo it restores immunological balance by acting on JAK/STAT/SOCS signaling, inhibiting JAK2, STAT3, and STAT6 phosphorylation and increasing SOCS1, SOCS3, and PIAS3 expression (Zhang et al., 2016a). Furthermore, some in vitro and in vivo studies show that Cur can downregulate TLR4, MyD88, and NF- $\mathrm{BB}$ signaling at neuronal level by inducing the release of proinflammatory cytokines (TNF- $\alpha$, IL- $1 \beta$, IL-6), producing an anti-inflammatory effect.

Cur is able to act on apoptosis and on mitochondrial biogenesis and dysfunction through SIRT activation by small molecules (Gupta et al., 2012). Cur can downregulate expression of growth factor receptors, transcription factors, TNFs, and nitric oxide synthase, and increase AMPK levels. In vascular smooth muscle cells, Cur promotes AMPK activation, which enhances superoxide and ATP production. This event stimulates an increase in $\mathrm{NAD}^{+}$levels and SIRT1 activation (Zendedel et al., 2018). Cur-induced SIRT1 upregulation has beneficial effects against a range of diseases including cardiac fibrosis, diabetes, and ischemia/reperfusion injury (Zendedel et al., 2018 \#7; Yang et al., 2013 \#5). The involvement of mitochondrial oxidative damage in several diseases such as MI/R is well known (Yang et al., 2013). Yang and colleagues investigated SIRT1 action after Cur treatment and the manner in which Cur might attenuate MI/ $\mathrm{R}$-induced mitochondrial oxidative damage. In vivo and in vitro experiments on rat heart and cardiomyocytes showed that Cur pre-treatment had protective effects, decreasing myocardial infarct size (Yang et al., 2013). Heart injury and mitochondrial oxidative damage are characterized by ROS overproduction and a reduction in succinate dehydrogenase or COX activity, leading to mitochondrial respiratory chain deficiency (Yang et al., 2013). Cardiomyocytes treated by Cur displayed upregulation of SIRT1, $\mathrm{COX}$, and succinate dehy-drogenase (SDH), and downregulation of Bax. These effects were abolished when cardiomyocytes were treated with SIRT1 siRNA. In these conditions, the levels of decreased SIRT1 abolished the effects of Cur treatment. These findings show that Cur-induced cardio-protection was mediated by SIRT1 (Yang et al., 2013). T2D is a chronic illness requiring continuing care to prevent long-term and acute complications. Cur may have positive effects in T2D by mediating the reduction of NF- $\kappa \mathrm{B}$ expression in inflammatory pathway (Zendedel et al., 2018). NF- $\kappa B$ deregulation can influence other mechanisms in which SIRT1 and AMPK are involved, such as glucose absorption in skeletal muscle. Data obtained in diabetic mice models showed that supplementation of Cur for 8 weeks might promote indirect activation of SIRT1 through AMPK (JimenezFlores et al., 2014).

Over time, preclinical studies have shown that Cur can act in various human diseases including immunodeficiency, virus infections, rheumatoid arthritis, myocardial infarction, atherosclerosis, and diabetes (Hsu and Cheng, 2007). A phase I study was published for the first time in 2001. Patients were subjected to five different Cur doses $(500,1,000,2,000,4,000$, and $8,000 \mathrm{mg}$ ) every day for 3 months, and data showed that Cur treatment up to $8,000 \mathrm{mg} /$ day is not toxic (Hsu and Cheng, 2007). Another study investigated Cur-mediated effects in patients with chronic non-alcoholic pancreatitis, showing that patients had a strong reversal of lipid peroxidation (Durgaprasad et al., 2005). The development of new routes of administration and new formulations of Cur with better bioavailability could be fundamental for future therapeutic strategies.

A list of completed and terminated clinical trials investigating the effects of Cur in metabolic and inflammatory diseases is reported in Table 5. A phase 2 clinical study (NCT01925547) investigated the effect of Cur micelles on inflammation and lipid metabolism markers in subjects at risk for metabolic syndrome. Two other trials, a phase 2 (NCT02017353) and a phase 3 (NCT02099890) study, investigated the effect of Cur on inflammation induced by endometrial carcinoma and spinal cord injury, respectively. Interesting results from three phase 2/ 3 clinical studies showed that Cur (as capsules or gel) prevents or reduces radiation-induced dermatitis in breast cancer patients receiving radiotherapy, enhancing the function of normal tissues (NCT01246973, NCT01042938, NCT02556632).

\section{Fisetin}

The dietary flavonoid fisetin (3,3',4,7-tetra-hydroxyflavone) is a natural polyphenol present in plants and fruits such as apples, persimmons, grapes, onions, kiwi, kale, and strawberries, whose daily intake is estimated to be about $0.4 \mathrm{mg}$ (Khan et al., 2013). This human diet constituent is reported to exert some beneficial anticancer, cardiovascular preventive, anti-inflammatory, and antioxidant effects that support normal cell homeostasis and cytoprotection (Chen et al., 2015; Kim et al., 2015). Fisetin was shown to have neuroprotective activity in various Huntington's disease models through ERK activation and to inhibit melanoma growth by suppressing Akt/mTOR1 pathway (Sechi et al., 2018). A recent study reported that fisetin reduces myocardial tissue damage in a reperfusion ischemia model by suppressing mitochondrial oxidative stress and inhibiting glycogen synthase kinase $3 \beta$ (Shanmugam et al., 2018). As a polyphenol, fisetin can counteract oxidative stress and mediate immune response via AMPK/SIRT1 and Nfr2 pathways (see Figure 1). Fisetin was shown to increase SIRT1 expression and enhance SIRT1mediated PPAR and FOXO1 deacetylation in 3T3L1 cells (Kim et al., 2015). Specifically, fisetin enhanced the association between SIRT1 and the PPAR $\gamma$ promoter, leading to a block of its transcriptional activity, adipogenesis, and lipid accumulation (Kim et al., 2015). Lipid accumulation is a common feature in 
TABLE 5 | Curcumin in clinical trials for metabolic and inflammatory disorders.

\begin{tabular}{|c|c|c|c|c|c|}
\hline Status & Study Title & Conditions & Intervention & Phase & NCT Number \\
\hline Completed & Micellar Curcumin and Metabolic Syndrome Biomarkers & $\begin{array}{l}\text { Metabolic Syndrome, Protection } \\
\text { Against }\end{array}$ & $\begin{array}{l}20 \text { mg of curcumin at the } \\
\text { beginning, after } 3 \text { and } 6 \\
\text { weeks }\end{array}$ & Phase 2 & NCT01925547 \\
\hline Completed & $\begin{array}{l}\text { Effect of Curcumin Addition to Standard Treatment on } \\
\text { Tumour-induced Inflammation in Endometrial Carcinoma }\end{array}$ & Endometrial Carcinoma & $2 \mathrm{~g}$ daily for 2 weeks & Phase 2 & NCT02017353 \\
\hline Completed & $\begin{array}{l}\text { The Effect of Diet on Chronic Inflammation and Related } \\
\text { Disorders Following Spinal Cord Injury }\end{array}$ & $\begin{array}{l}\text { Neuropathic Pain, Depression, } \\
\text { Cognitive Impairment }\end{array}$ & $\begin{array}{l}400 \mathrm{mg} \\
\text { Baseline/3 months/6 } \\
\text { months }\end{array}$ & Phase 3 & NCT02099890 \\
\hline $\begin{array}{l}\text { Completed } \\
\text { with results }\end{array}$ & Oral Curcumin for Radiation Dermatitis & $\begin{array}{l}\text { Radiation-induced Dermatitis, } \\
\text { Breast cancer }\end{array}$ & $\begin{array}{l}2 \text { g } 3 \text { times daily for } 1 \\
\text { week }\end{array}$ & Phase 2/3 & NCT01246973 \\
\hline $\begin{array}{l}\text { Completed } \\
\text { with results }\end{array}$ & $\begin{array}{l}\text { Curcumin for the Prevention of Radiation-induced Dermatitis } \\
\text { in Breast Cancer Patients }\end{array}$ & & $\begin{array}{l}2 \text { g } 3 \text { times daily }(\sim 4-7 \\
\text { weeks) }\end{array}$ & Phase 2 & NCT01042938 \\
\hline $\begin{array}{l}\text { Completed } \\
\text { with results }\end{array}$ & $\begin{array}{l}\text { Prophylactic Topical Agents in Reducing Radiation-Induced } \\
\text { Dermatitis in Patients With Non-inflammatory Breast Cancer } \\
\text { (Curcumin-II) }\end{array}$ & $\begin{array}{l}\text { Breast Carcinoma, Breast } \\
\text { Carcinoma, Pain, Radiation- } \\
\text { Induced Dermatitis, }\end{array}$ & & Phase 2 & NCT02556632 \\
\hline
\end{tabular}

NAFLD (Liou et al., 2018). Increased fatty acid synthesis and hepatocyte accumulation is associated with metabolic disorder (Liou et al., 2018). Fisetin treatment in NAFLD mice reduced epididymal adipose tissue, hepatocyte steatosis, and fatty acid synthesis. The data reported by Liou et al. showed an increase in AMPK $\alpha$ phosphorylation and SIRT1 expression levels, while in vitro results revealed a reduction in lipid accumulation and an increase in lipolysis. The beneficial effects of fisetin were also linked to its action as a caloric restriction mimetic (CRM) (Singh et al., 2018). Natural compounds such as metformin and resveratrol display the ability to mimic the effects of caloric restriction, acting on stress response and metabolic pathways (Ingram et al., 2006). A recent study investigated the neuroprotective effects of fisetin as a possible CRM against apoptosis, oxidative stress, aging, and neurodegeneration (Singh et al., 2018). The authors showed that aging of rat brain induced an increase in pro-inflammatory cytokines and that treatment with CRMs such as metformin can reduce inflammation (Singh et al., 2019). In an attempt to demonstrate that fisetin could have beneficial effects against neuroinflammation comparable to metformin, Singh et al. showed that fisetin mediated protective effects via SIRT1 activation, enhancing NF- $\mathrm{KB}$ deacetylation and promoting inhibition of pro-inflammatory gene expression (Singh et al., 2019). Data suggested that fisetin may be a suitable therapeutic candidate for aging and neurological diseases.
However, there are only six currently available clinical trials using fisetin, most of which are still recruiting (Table 6). These pilot studies aim to test the anti-inflammatory efficacy of fisetin in Frail Elderly Syndrome (NCT03675724 and NCT03430037) and in symptomatic knee osteoarthritis patients (NCT04210986). Another phase 2 clinical study (NCT03325322) intends to evaluate the effects of oral fisetin on adipose tissue-derived mesenchymal stem/stromal cell function, kidney function, inflammation, and physical function in subjects with chronic kidney diseases and diabetes.

\section{CONCLUSIONS}

In vitro and in vivo studies as well as clinical trials in humans show that SIRT-activating compounds derived from natural sources could preserve human health and might prove beneficial for the prevention and treatment of a plethora of human diseases. The fact that many of these natural molecules are introduced through diet underscores the importance of dietary intervention to correct predisposition and life-style disorders. However, it remains unclear whether (or not) the effects of these compounds are mostly related to SIRT activation and what drug dose/concentration is required. Since most of the natural compounds described here exhibit pleiotropic effects, determining a direct link between SIRT activation and

TABLE 6 | Fisetin in clinical trials for inflammatory disorders.

\begin{tabular}{|c|c|c|c|c|c|}
\hline Status & Study Title & Conditions & Intervention & Phase & NCT Number \\
\hline Recruiting & $\begin{array}{l}\text { Alleviation by Fisetin of Frailty, Inflammation, } \\
\text { and Related Measures in Older Adults }\end{array}$ & Frail Elderly Syndrome & $\begin{array}{l}20 \mathrm{mg} / \mathrm{kg} \text { daily orally for } 2 \text { consecutive } \\
\text { days }\end{array}$ & Phase 2 & NCT03675724 \\
\hline Recruiting & $\begin{array}{l}\text { Alleviation by Fisetin of Frailty, Inflammation, } \\
\text { and Related Measures in Older Women }\end{array}$ & Frail Elderly Syndrome & $\begin{array}{l}20 \mathrm{mg} / \mathrm{kg} \text { daily orally for } 2 \text { consecutive } \\
\text { days, for } 2 \text { consecutive months. }\end{array}$ & Phase 2 & NCT03430037 \\
\hline Recruiting & $\begin{array}{l}\text { Senolytic Drugs Attenuate Osteoarthritis- } \\
\text { Related Articular Cartilage Degeneration: A } \\
\text { Clinical Trial }\end{array}$ & Osteoarthritis, Knee & $\begin{array}{l}20 \mathrm{mg} / \mathrm{kg} \text { for } 2 \text { consecutive days, followed } \\
\text { by } 28 \text { days off, then } 2 \text { more consecutive } \\
\text { days }\end{array}$ & Phase 1/2 & NCT04210986 \\
\hline Recruiting & $\begin{array}{l}\text { Inflammation and Stem Cells in Diabetic and } \\
\text { Chronic Kidney Disease }\end{array}$ & $\begin{array}{l}\text { Chronic Kidney Diseases, } \\
\text { Diabetes Mellitus, Diabetic } \\
\text { Nephropathies }\end{array}$ & $\begin{array}{l}20 \mathrm{mg} / \mathrm{kg} \text { daily orally for } 2 \text { consecutive } \\
\text { days }\end{array}$ & Phase 2 & NCT03325322 \\
\hline
\end{tabular}


improvement in human health is very challenging. It is also evident that a more robust correlation between health effects and administration of the bioactive compounds needs to be established in order to understand their biological impact and their direct association with SIRT activation. An additional issue is that, although numerous studies have been carried out, the majority only address the role of SIRT1 and its pharmacological regulation. Our current knowledge of the potential pharmacological activation of the expression/activity of other SIRTs is largely incomplete. A greater insight into the selectivity and specificity of natural SIRT activators may help understand the myriad beneficial effects described to date. A further question is related to the cell/context-specific expression of some SIRTs, cofactor availability, and context-specific action of some of the described modulators. Further investigations will be required to provide a more detailed understanding. In addition, some natural SIRT modulators, such as Cur, display poor bioavailability and solubility. Treatment with higher bioavailable preparations of Cur derivatives may result in increased SIRT1-activating action, further substantiating the link between SIRT1, Cur, and therapeutic effects. The fact that studies indicate that the majority of SIRT activators (or at least SIRT1-targeting activators) exert both direct activating effects and indirect effects via modulation of SIRT1 downstream pathways complicates the interpretation of results and, particularly, the mining of data specifically dependent on direct SIRT1 binding and activation. Similarly, the activating effects resulting from SIRT1 binding are reported to be either dependent on the catalytic domain or related to different domains, leaving considerable uncertainty as to the activating

\section{REFERENCES}

Abdelsamia, E. M., Khaleel, S. A., Balah, A., and Abdel Baky, N. A. (2019). Curcumin augments the cardioprotective effect of metformin in an experimental model of type I diabetes mellitus; Impact of $\mathrm{Nrf} 2 / \mathrm{HO}-1$ and JAK/STAT pathways. BioMed. Pharmacother. 109, 2136-2144. doi: 10.1016/ j.biopha.2018.11.064

Araki, T., Sasaki, Y., and Milbrandt, J. (2004). Increased nuclear NAD biosynthesis and SIRT1 activation prevent axonal degeneration. Science 305 (5686), 10101013. doi: 10.1126/science.1098014

Bai, X., Yao, L., Ma, X., and Xu, X. (2018). Small Molecules as SIRT Modulators. Mini Rev. Med. Chem. 18 (13), 1151-1157. doi: 10.2174/13895575166661606 20095103

Biason-Lauber, A., Boni-Schnetzler, M., Hubbard, B. P., Bouzakri, K., Brunner, A., Cavelti-Weder, C., et al. (2013). Identification of a SIRT1 mutation in a family with type 1 diabetes. Cell Metab. 17 (3), 448-455. doi: 10.1016/j.cmet. 2013.02.001

Brasnyo, P., Molnar, G. A., Mohas, M., Marko, L., Laczy, B., Cseh, J., et al. (2011). Resveratrol improves insulin sensitivity, reduces oxidative stress and activates the Akt pathway in type 2 diabetic patients. Br. J. Nutr. 106 (3), 383-389. doi: 10.1017/S0007114511000316

Brunet, A., Sweeney, L. B., Sturgill, J. F., Chua, K. F., Greer, P. L., Lin, Y., et al. (2004). Stress-dependent regulation of FOXO transcription factors by the SIRT1 deacetylase. Science 303 (5666), 2011-2015. doi: 10.1126/science. 1094637

Capiralla, H., Vingtdeux, V., Zhao, H., Sankowski, R., Al-Abed, Y., Davies, P., et al. (2012). Resveratrol mitigates lipopolysaccharide- and Abeta-mediated microglial inflammation by inhibiting the TLR4/NF-kappaB/STAT signaling binding mode and its context specificity upon drug response. Despite the generally encouraging data from in vitro and in vivo studies, supporting molecular evidence providing clues to these unanswered questions is still lacking. A better understanding of the molecular mechanisms of these natural molecules (or their derivatives) may lead to further and more focused development of their preclinical and clinical use.

\section{AUTHOR CONTRIBUTIONS}

CI, MS, AN, and LA contributed to the redaction of the manuscript and gave final approval of the manuscript.

\section{FUNDING}

Authors were supported by VALERE: Vanvitelli per la Ricerca Program, MIUR20152TE5PK, EPICHEMBIO CM1406, the Campania Regional Government Lotta alle Patologie Oncologiche iCURE (CUP B21c17000030007), Campania Regional Government FASE 2:IDEAL (CUP B63D18000560007), MIUR Proof of Concept (POC01_00043), Vanvitelli per la Ricerca Program "AdipCare" (ID 263).

\section{ACKNOWLEDGMENTS}

We thank C. Fisher for linguistic editing. cascade. J. Neurochem. 120 (3), 461-472. doi: 10.1111/j.1471-4159.2011. 07594.x

Cavalli, G., and Heard, E. (2019). Advances in epigenetics link genetics to the environment and disease. Nature 571 (7766), 489-499. doi: 10.1038/s41586019-1411-0

Chang, H. C., and Guarente, L. (2014). SIRT1 and other sirtuins in metabolism. Trends Endocrinol. Metab. 25 (3), 138-145. doi: 10.1016/j.tem.2013.12.001

Chaplin, A., Carpene, C., and Mercader, J. (2018). Resveratrol, Metabolic Syndrome, and Gut Microbiota. Nutrients 10 (11), 1651. doi: 10.3390/nu10111651

Chassot, L. N., Scolaro, B., Roschel, G. G., Cogliati, B., Cavalcanti, M. F., Abdalla, D. S. P., et al. (2018). Comparison between red wine and isolated transresveratrol on the prevention and regression of atherosclerosis in LDLr $((-/-))$ mice. J. Nutr. Biochem. 61, 48-55. doi: 10.1016/j.jnutbio.2018.07.014

Cheang, W. S., Wong, W. T., Wang, L., Cheng, C. K., Lau, C. W., Ma, R. C. W., et al. (2019). Resveratrol ameliorates endothelial dysfunction in diabetic and obese mice through sirtuin 1 and peroxisome proliferator-activated receptor delta. Pharmacol. Res. 139, 384-394. doi: 10.1016/j.phrs.2018.11.041

Chen, D. L., and Yang, K. Y. (2017). Berberine Alleviates Oxidative Stress in Islets of Diabetic Mice by Inhibiting miR-106b Expression and Up-Regulating SIRT1. J. Cell Biochem. 118 (12), 4349-4357. doi: 10.1002/jcb.26089

Chen, Z., Shentu, T. P., Wen, L., Johnson, D. A., and Shyy, J. Y. (2013). Regulation of SIRT1 by oxidative stress-responsive miRNAs and a systematic approach to identify its role in the endothelium. Antioxid. Redox Signal 19 (13), 1522-1538. doi: 10.1089/ars.2012.4803

Chen, P. Y., Ho, Y. R., Wu, M. J., Huang, S. P., Chen, P. K., Tai, M. H., et al. (2015). Cytoprotective effects of fisetin against hypoxia-induced cell death in PC12 cells. Food Funct. 6 (1), 287-296. doi: 10.1039/c4fo00948g

Cicero, A. F., and Baggioni, A. (2016). Berberine and Its Role in Chronic Disease. Adv. Exp. Med. Biol. 928, 27-45. doi: 10.1007/978-3-319-41334-1_2 
Costa, L. G., Garrick, J. M., Roque, P. J., and Pellacani, C. (2016). Mechanisms of Neuroprotection by Quercetin: Counteracting Oxidative Stress and More. Oxid. Med. Cell Longev. 2016:2986796. doi: 10.1155/2016/2986796

Cui, Y., Han, Y., Yang, X., Sun, Y., and Zhao, Y. (2013). Protective effects of quercetin and quercetin-5',8-disulfonate against carbon tetrachloride-caused oxidative liver injury in mice. Molecules 19 (1), 291-305. doi: 10.3390/ molecules19010291

de Boer, V. C., de Goffau, M. C., Arts, I. C., Hollman, P. C., and Keijer, J. (2006). SIRT1 stimulation by polyphenols is affected by their stability and metabolism. Mech. Ageing Dev. 127 (7), 618-627. doi: 10.1016/j.mad.2006.02.007

Del Rio, D., Rodriguez-Mateos, A., Spencer, J. P., Tognolini, M., Borges, G., and Crozier, A. (2013). Dietary (poly)phenolics in human health: structures, bioavailability, and evidence of protective effects against chronic diseases. Antioxid. Redox Signal 18 (14), 1818-1892. doi: 10.1089/ars.2012.4581

Donniacuo, M., Urbanek, K., Nebbioso, A., Sodano, L., Gallo, L., Altucci, L., et al. (2019). Cardioprotective effect of a moderate and prolonged exercise training involves sirtuin pathway. Life Sci. 222, 140-147. doi: 10.1016/ j.lfs.2019.03.001

D’Angelo, S., Scafuro, M., and Meccariello, R. (2019). BPA and Nutraceuticals, Simultaneous Effects on Endocrine Functions. Endocr. Metab. Immune Disord. Drug Targets 19 (5), 594-604. doi: 10.2174/1871530319666190101120119

Durgaprasad, S., Pai, C. G.Vasanthkumar, , Alvres, J. F., Namitha, S. (2005). A pilot study of the antioxidant effect of curcumin in tropical pancreatitis. Indian J. Med. Res. 122 (4), 315-318.

Endale, M., Park, S. C., Kim, S., Kim, S. H., Yang, Y., Cho, J. Y., et al. (2013). Quercetin disrupts tyrosine-phosphorylated phosphatidylinositol 3-kinase and myeloid differentiation factor-88 association, and inhibits MAPK/AP-1 and IKK/NF-kappaB-induced inflammatory mediators production in RAW 264.7 cells. Immunobiology 218 (12), 1452-1467. doi: 10.1016/j.imbio.2013.04.019

Fourny, N., Lan, C., Seree, E., Bernard, M., and Desrois, M. (2019). Protective Effect of Resveratrol against Ischemia-Reperfusion Injury via Enhanced High Energy Compounds and eNOS-SIRT1 Expression in Type 2 Diabetic Female Rat Heart. Nutrients 11 (1), 105. doi: 10.3390/nu11010105

Galleggiante, V., De Santis, S., Liso, M., Verna, G., Sommella, E., Mastronardi, M., et al. (2019). Quercetin-Induced miR-369-3p Suppresses Chronic Inflammatory Response Targeting C/EBP-beta. Mol. Nutr. Food Res. 63 (19), e1801390. doi: 10.1002/mnfr.201801390

Geraets, L., Moonen, H. J., Brauers, K., Wouters, E. F., Bast, A., and Hageman, G. J. (2007). Dietary flavones and flavonoles are inhibitors of poly(ADP-ribose) polymerase-1 in pulmonary epithelial cells. J. Nutr. 137 (10), 2190-2195. doi: $10.1093 /$ jn/137.10.2190

Geto, Z., Molla, M. D., Challa, F., Belay, Y., and Getahun, T. (2020). Mitochondrial Dynamic Dysfunction as a Main Triggering Factor for Inflammation Associated Chronic Non-Communicable Diseases. J. Inflammation Res. 13, 97-107. doi: 10.2147/JIR.S232009

Ghanim, H., Sia, C. L., Abuaysheh, S., Korzeniewski, K., Patnaik, P., Marumganti, A., et al. (2010). An antiinflammatory and reactive oxygen species suppressive effects of an extract of Polygonum cuspidatum containing resveratrol. J. Clin. Endocrinol. Metab. 95 (9), E1-E8. doi: 10.1210/jc.2010-0482

Gu, X., Han, D., Chen, W., Zhang, L., Lin, Q., Gao, J., et al. (2016). SIRT1mediated FoxOs pathways protect against apoptosis by promoting autophagy in osteoblast-like MC3T3-E1 cells exposed to sodium fluoride. Oncotarget 7 (40), 65218-65230. doi: 10.18632/oncotarget.11573

Guimaraes, M. R., Leite, F. R., Spolidorio, L. C., Kirkwood, K. L., and Rossa, C.Jr. (2013). Curcumin abrogates LPS-induced pro-inflammatory cytokines in RAW 264.7 macrophages. Evidence for novel mechanisms involving SOCS1, -3 and p38 MAPK. Arch. Oral. Biol. 58 (10), 1309-1317. doi: 10.1016/ j.archoralbio.2013.07.005

Gupta, S. C., Patchva, S., Koh, W., and Aggarwal, B. B. (2012). Discovery of curcumin, a component of golden spice, and its miraculous biological activities. Clin. Exp. Pharmacol. Physiol. 39 (3), 283-299. doi: 10.1111/j.14401681.2011.05648.x

Gupta, P. K., DiPette, D. J., and Supowit, S. C. (2014). Protective effect of resveratrol against pressure overload-induced heart failure. Food Sci. Nutr. 2 (3), 218-229. doi: 10.1002/fsn3.92

Haigis, M. C., and Sinclair, D. A. (2010). Mammalian sirtuins: biological insights and disease relevance. Annu. Rev. Pathol. 5, 253-295. doi: 10.1146/annurev. pathol.4.110807.092250
Halliwell, B., Rafter, J., and Jenner, A. (2005). Health promotion by flavonoids, tocopherols, tocotrienols, and other phenols: direct or indirect effects? Antioxidant or not? Am. J. Clin. Nutr. 81 (1 Suppl), 268S-276S. doi: 10.1093/ ajcn/81.1.268S

Han, X., Zhang, L. U., Liu, Y., Wu, M., Li, X., Zhang, Z. T., et al. (2020). Resveratrol protects H9c2 cells against hypoxia-induced apoptosis through miR-30d-5p/ SIRT1/NF-kappaB axis. J. Biosci. 45, 42. doi: 10.1007/s12038-020-9997-9

Hasanein, P., Ghafari-Vahed, M., and Khodadadi, I. (2017). Effects of isoquinoline alkaloid berberine on lipid peroxidation, antioxidant defense system, and liver damage induced by lead acetate in rats. Redox Rep. 22 (1), 42-50. doi: 10.1080/ 13510002.2016.1140406

Hsu, C. H., and Cheng, A. L. (2007). Clinical studies with curcumin. Adv. Exp. Med. Biol. 595, 471-480. doi: 10.1007/978-0-387-46401-5_21

Hsu, C. P., Zhai, P., Yamamoto, T., Maejima, Y., Matsushima, S., Hariharan, N., et al. (2010). Silent information regulator 1 protects the heart from ischemia/reperfusion. Circulation 122 (21), 2170-2182. doi: 10.1161/CIRCULATIONAHA.110.958033

Hu, T., Shi, J. J., Fang, J., Wang, Q., Chen, Y. B., and Zhang, S. J.. (2020). Quercetin ameliorates diabetic encephalopathy through SIRT1/ER stress pathway in $\mathrm{db} /$ db mice. Aging 12 (8), 7015-7029. doi: 10.18632/aging.103059

Huang, S. X., Qiu, G., Cheng, F. R., Pei, Z., Yang, Z., Deng, X. H., et al. (2018). Berberine Protects Secondary Injury in Mice with Traumatic Brain Injury Through Anti-oxidative and Anti-inflammatory Modulation. Neurochem. Res. 43 (9), 1814-1825. doi: 10.1007/s11064-018-2597-5

Hung, C. H., Chan, S. H., Chu, P. M., and Tsai, K. L. (2015). Quercetin is a potent anti-atherosclerotic compound by activation of SIRT1 signaling under oxLDL stimulation. Mol. Nutr. Food Res. 59 (10), 1905-1917. doi: 10.1002/ mnfr.201500144

Hwang, J. M., Kuo, H. C., Tseng, T. H., Liu, J. Y., and Chu, C. Y. (2006). Berberine induces apoptosis through a mitochondria/caspases pathway in human hepatoma cells. Arch. Toxicol. 80 (2), 62-73. doi: 10.1007/s00204-005-0014-8

Ingram, D. K., Zhu, M., Mamczarz, J., Zou, S., Lane, M. A., Roth, G. S., et al. (2006). Calorie restriction mimetics: an emerging research field. Aging Cell 5 (2), 97-108. doi: 10.1111/j.1474-9726.2006.00202.x

Iskender, H., Dokumacioglu, E., Sen, T. M., Ince, I., Kanbay, Y., and Saral, S. (2017). The effect of hesperidin and quercetin on oxidative stress, NF-kappaB and SIRT1 levels in a STZ-induced experimental diabetes model. BioMed. Pharmacother. 90, 500-508. doi: 10.1016/j.biopha.2017.03.102

Jimenez-Flores, L. M., Lopez-Briones, S., Macias-Cervantes, M. H., RamirezEmiliano, J., and Perez-Vazquez, V. (2014). A PPARgamma, NF-kappaB and AMPK-dependent mechanism may be involved in the beneficial effects of curcumin in the diabetic $\mathrm{db} / \mathrm{db}$ mice liver. Molecules 19 (6), 8289-8302. doi: 10.3390/molecules19068289

Kauppinen, A., Suuronen, T., Ojala, J., Kaarniranta, K., and Salminen, A. (2013). Antagonistic crosstalk between NF-kappaB and SIRT1 in the regulation of inflammation and metabolic disorders. Cell Signal 25 (10), 1939-1948. doi: 10.1016/j.cellsig.2013.06.007

Khan, N., Syed, D. N., Ahmad, N., and Mukhtar, H. (2013). Fisetin: a dietary antioxidant for health promotion. Antioxid. Redox Signal 19 (2), 151-162. doi: 10.1089/ars.2012.4901

Kim, S. C., Kim, Y. H., Son, S. W., Moon, E. Y., Pyo, S., and Um, S. H. (2015). Fisetin induces Sirt1 expression while inhibiting early adipogenesis in 3T3-L1 cells. Biochem. Biophys. Res. Commun. 467 (4), 638-644. doi: 10.1016/ j.bbrc.2015.10.094

Konrad, M., and Nieman, D. C. (2015). "Evaluation of Quercetin as a Countermeasure to Exercise-Induced Physiological Stress," in Antioxidants in Sport Nutrition. Ed. M. Lamprecht (Boca Raton, FL: CRC Press/Taylor \& Francis)

Kris-Etherton, P. M., Hecker, K. D., Bonanome, A., Coval, S. M., Binkoski, A. E., Hilpert, K. F., et al. (2002). Bioactive compounds in foods: their role in the prevention of cardiovascular disease and cancer. Am. J. Med. 113 Suppl 9B, 71S-88S. doi: 10.1016/s0002-9343(01)00995-0

Kupis, W., Palyga, J., Tomal, E., and Niewiadomska, E. (2016). The role of sirtuins in cellular homeostasis. J. Physiol. Biochem. 72 (3), 371-380. doi: 10.1007/ s13105-016-0492-6

Lara-Guzman, O. J., Gil-Izquierdo, A., Medina, S., Osorio, E., Alvarez-Quintero, R., Zuluaga, N., et al. (2018). Oxidized LDL triggers changes in oxidative stress and inflammatory biomarkers in human macrophages. Redox Biol. 15, 1-11. doi: 10.1016/j.redox.2017.11.017 
Lee, S. H., and Min, K. J. (2013). Caloric restriction and its mimetics. BMB Rep. 46 (4), 181-187. doi: 10.5483/bmbrep.2013.46.4.033

Li, Y., Yao, J., Han, C., Yang, J., Chaudhry, M. T., Wang, S., et al. (2016). Quercetin, Inflammation and Immunity. Nutrients 8 (3):167. doi: 10.3390/nu8030167

Li, L., Wang, X., Sharvan, R., Gao, J., and Qu, S. (2017). Berberine could inhibit thyroid carcinoma cells by inducing mitochondrial apoptosis, G0/G1 cell cycle arrest and suppressing migration via PI3K-AKT and MAPK signaling pathways. BioMed. Pharmacother. 95, 1225-1231. doi: 10.1016/j.biopha. 2017.09.010

Li, P., Song, X., Zhang, D., Guo, N., Wu, C., Chen, K., et al. (2020a). Resveratrol improves left ventricular remodeling in chronic kidney disease via Sirt1mediated regulation of FoxO1 activity and MnSOD expression. Biofactors 46 (1), 168-179. doi: 10.1002/biof.1584

Li, Z., Jiang, T., Lu, Q., Xu, K., He, J., Xie, L., et al. (2020b). Berberine attenuated the cytotoxicity induced by t-BHP via inhibiting oxidative stress and mitochondria dysfunction in PC-12 cells. Cell Mol. Neurobiol. 40 (4), 587602. doi: 10.1007/s10571-019-00756-7

Liguori, I., Russo, G., Curcio, F., Bulli, G., Aran, L., Della-Morte, D., et al. (2018). Oxidative stress, aging, and diseases. Clin. Interv. Aging 13, 757-772. doi: 10.2147/CIA.S158513

Liou, C. J., Wei, C. H., Chen, Y. L., Cheng, C. Y., Wang, C. L., and Huang, W. C. (2018). Fisetin Protects Against Hepatic Steatosis Through Regulation of the Sirt1/AMPK and Fatty Acid beta-Oxidation Signaling Pathway in High-Fat Diet-Induced Obese Mice. Cell Physiol. Biochem. 49 (5), 1870-1884. doi: $10.1159 / 000493650$

Ma, X., Sun, Z., Han, X., Li, S., Jiang, X., Chen, S., et al. (2019). Neuroprotective Effect of Resveratrol via Activation of Sirt1 Signaling in a Rat Model of Combined Diabetes and Alzheimer's Disease. Front. Neurosci. 13:1400:1400. doi: $10.3389 /$ fnins. 2019.01400

Malaguarnera, L. (2019). Influence of Resveratrol on the Immune Response. Nutrients 11 (5), 946. doi: 10.3390/nu11050946

McCubrey, J. A., Lertpiriyapong, K., Steelman, L. S., Abrams, S. L., Yang, L. V., Murata, R. M., et al. (2017). Effects of resveratrol, curcumin, berberine and other nutraceuticals on aging, cancer development, cancer stem cells and microRNAs. Aging (Albany NY) 9 (6), 1477-1536. doi: 10.18632/aging.101250

Mercurio, V., Pucci, G., Bosso, G., Fazio, V., Battista, F., Iannuzzi, A., et al. (2020). A nutraceutical combination reduces left ventricular mass in subjects with metabolic syndrome and left ventricular hypertrophy: A multicenter, randomized, double-blind, placebo-controlled trial. Clin. Nutr. 39 (5), 13791384. doi: 10.1016/j.clnu.2019.06.026

Miceli, M., Bontempo, P., Nebbioso, A., and Altucci, L. (2014). Natural compounds in epigenetics: a current view. Food Chem. Toxicol. 73, 71-83. doi: 10.1016/j.fct.2014.08.005

Muthian, G., and Bright, J. J. (2004). Quercetin, a flavonoid phytoestrogen, ameliorates experimental allergic encephalomyelitis by blocking IL-12 signaling through JAK-STAT pathway in T lymphocyte. J. Clin. Immunol. 24 (5), 542-552. doi: 10.1023/B:JOCI.0000040925.55682.a5

Nabavi, S. F., Nabavi, S. M., Mirzaei, M., and Moghaddam, A. H. (2012). Protective effect of quercetin against sodium fluoride induced oxidative stress in rat's heart. Food Funct. 3 (4), 437-441. doi: 10.1039/c2fo10264a

Nair, M. P., Kandaswami, C., Mahajan, S., Chadha, K. C., Chawda, R., Nair, H., et al. (2002). The flavonoid, quercetin, differentially regulates Th-1 (IFNgamma) and Th-2 (IL4) cytokine gene expression by normal peripheral blood mononuclear cells. Biochim. Biophys. Acta 1593 (1), 29-36. doi: 10.1016/ s0167-4889(02)00328-2

Oboh, G., Ademosun, A. O., and Ogunsuyi, O. B. (2016). Quercetin and Its Role in Chronic Diseases. Adv. Exp. Med. Biol. 929, 377-387. doi: 10.1007/978-3-31941342-6_17

O'Callaghan, C., and Vassilopoulos, A. (2017). Sirtuins at the crossroads of stemness, aging, and cancer. Aging Cell 16 (6), 1208-1218. doi: 10.1111/ acel. 12685

Pang, B., Zhao, L. H., Zhou, Q., Zhao, T. Y., Wang, H., Gu, C. J., et al. (2015). Application of berberine on treating type 2 diabetes mellitus. Int. J. Endocrinol. 2015:905749. doi: 10.1155/2015/905749

Piotrowska, H., Kucinska, M., and Murias, M. (2012). Biological activity of piceatannol: leaving the shadow of resveratrol. Mutat. Res. 750 (1), 60-82. doi: 10.1016/j.mrrev.2011.11.001
Price, N. L., Gomes, A. P., Ling, A. J., Duarte, F. V., Martin-Montalvo, A., North, B. J., et al. (2012). SIRT1 is required for AMPK activation and the beneficial effects of resveratrol on mitochondrial function. Cell Metab. 15 (5), 675-690. doi: 10.1016/j.cmet.2012.04.003

Priyadarsini, K. I. (2014). The chemistry of curcumin: from extraction to therapeutic agent. Molecules 19 (12), 20091-20112. doi: 10.3390/molecules 191220091

Qiu, L., Luo, Y., and Chen, X. (2018). Quercetin attenuates mitochondrial dysfunction and biogenesis via upregulated AMPK/SIRT1 signaling pathway in OA rats. BioMed. Pharmacother. 103, 1585-1591. doi: 10.1016/ j.biopha.2018.05.003

Ren, Z., He, H., Zuo, Z., Xu, Z., Wei, Z., and Deng, J. (2019). The role of different SIRT1-mediated signaling pathways in toxic injury. Cell Mol. Biol. Lett. 24, 36. doi: 10.1186/s11658-019-0158-9

Rodgers, J. T., Lerin, C., Haas, W., Gygi, S. P., Spiegelman, B. M., and Puigserver, P. (2005). Nutrient control of glucose homeostasis through a complex of PGC1alpha and SIRT1. Nature 434 (7029), 113-118. doi: 10.1038/nature03354

Romagnolo, D. F., and Selmin, O. I. (2017). Mediterranean Diet and Prevention of Chronic Diseases. Nutr. Today 52 (5), 208-222. doi: 10.1097/NT.0000000000000228

Ruan, H., Zhan, Y. Y., Hou, J., Xu, B., Chen, B., Tian, Y., et al. (2017). Berberine binds RXRalpha to suppress beta-catenin signaling in colon cancer cells. Oncogene 36 (50), 6906-6918. doi: 10.1038/onc.2017.296

Sampaio, S. F., Branco, A. F., Wojtala, A., Vega-Naredo, I., Wieckowski, M. R., and Oliveira, P. J. (2016). p66Shc signaling is involved in stress responses elicited by anthracycline treatment of rat cardiomyoblasts. Arch. Toxicol. 90 (7), 16691684. doi: $10.1007 / \mathrm{s} 00204-015-1583-9$

Savikin, K. P., Krstic-Milosevic, D. B., Menkovic, N. R., Beara, I. N., Mrkonjic, Z. O., and Pijevijakusic, D. S. (2017). Crataegus orientalis Leaves and Berries: Phenolic Profiles, Antioxidant and Anti-inflammatory Activity. Nat. Prod. Commun. 12 (2), 159-162.

Sechi, M., Lall, R. K., Afolabi, S. O., Singh, A., Joshi, D. C., Chiu, S. Y., et al. (2018). Fisetin targets YB-1/RSK axis independent of its effect on ERK signaling: insights from in vitro and in vivo melanoma models. Sci. Rep. 8 (1), 15726. doi: 10.1038/s41598-018-33879-w

Serafini, M. M., Catanzaro, M., Fagiani, F., Simoni, E., Caporaso, R., Dacrema, M., et al. (2019). Modulation of Keap1/Nrf2/ARE Signaling Pathway by Curcumaand Garlic-Derived Hybrids. Front. Pharmacol. 10:1597:1597. doi: 10.3389/ fphar.2019.01597

Shanmugam, K., Ravindran, S., Kurian, G. A., and Rajesh, M. (2018). Fisetin Confers Cardioprotection against Myocardial Ischemia Reperfusion Injury by Suppressing Mitochondrial Oxidative Stress and Mitochondrial Dysfunction and Inhibiting Glycogen Synthase Kinase 3beta Activity. Oxid. Med. Cell Longev. 2018:9173436. doi: 10.1155/2018/9173436

Shentu, T. P., He, M., Sun, X., Zhang, J., Zhang, F., Gongol, B., et al. (2016). AMPActivated Protein Kinase and Sirtuin 1 Coregulation of Cortactin Contributes to Endothelial Function. Arterioscler. Thromb. Vasc. Biol. 36 (12), 2358-2368. doi: 10.1161/ATVBAHA.116.307871

Singh, S., Singh, A. K., Garg, G., and Rizvi, S. I. (2018). Fisetin as a caloric restriction mimetic protects rat brain against aging induced oxidative stress, apoptosis and neurodegeneration. Life Sci. 193, 171-179. doi: 10.1016/ j.lfs.2017.11.004

Singh, S., Garg, G., Singh, A. K., Tripathi, S. S., and Rizvi, S. I. (2019). Fisetin, a potential caloric restriction mimetic, modulates ionic homeostasis in senescence induced and naturally aged rats. Arch. Physiol. Biochem., 1-8. doi: $10.1080 / 13813455.2019 .1662452$

Song, D., Hao, J., and Fan, D. (2020). Biological properties and clinical applications of berberine. Front. Med. doi: 10.1007/s11684-019-0724-6

Sun, T., Zhang, Y., Zhong, S., Gao, F., Chen, Y., Wang, B., et al. (2018). N-n-Butyl Haloperidol Iodide, a Derivative of the Anti-psychotic Haloperidol, Antagonizes Hypoxia/Reoxygenation Injury by Inhibiting an Egr-1/ROS Positive Feedback Loop in H9c2 Cells. Front. Pharmacol. 9:19:19. doi: $10.3389 /$ fphar.2018.00019

Svajger, U., and Jeras, M. (2012). Anti-inflammatory effects of resveratrol and its potential use in therapy of immune-mediated diseases. Int. Rev. Immunol. 31 (3), 202-222. doi: 10.3109/08830185.2012.665108

Tang, J., Lu, L., Liu, Y., Ma, J., Yang, L., Li, L., et al. (2019). Quercetin improve ischemia/reperfusion-induced cardiomyocyte apoptosis in vitro and in vivo 
study via SIRT1/PGC-1alpha signaling. J. Cell Biochem. 120 (6), 9747-9757. doi: $10.1002 / j c b .28255$

Theodotou, M., Fokianos, K., Mouzouridou, A., Konstantinou, C., Aristotelous, A., Prodromou, D., et al. (2017). The effect of resveratrol on hypertension: A clinical trial. Exp. Ther. Med. 13 (1), 295-301. doi: 10.3892/etm.2016.3958

Tian, X. Y., Wong, W. T., Wang, N., Lu, Y., Cheang, W. S., Liu, J., et al. (2012). PPARdelta activation protects endothelial function in diabetic mice. Diabetes 61 (12), 3285-3293. doi: $10.2337 / \mathrm{db} 12-0117$

Wafi, A. M., Hong, J., Rudebush, T. L., Yu, L., Hackfort, B., Wang, H., et al. (2019). Curcumin improves exercise performance of mice with coronary artery ligationinduced HFrEF: Nrf2 and antioxidant mechanisms in skeletal muscle. J. Appl. Physiol. (1985) 126 (2), 477-486. doi: 10.1152/japplphysiol.00654.2018

Waldman, M., Cohen, K., Yadin, D., Nudelman, V., Gorfil, D., Laniado-Schwartzman, M., et al. (2018). Regulation of diabetic cardiomyopathy by caloric restriction is mediated by intracellular signaling pathways involving 'SIRT1 and PGC-1alpha'. Cardiovasc. Diabetol. 17 (1), 111. doi: 10.1186/s12933-018-0754-4

Wan, D., Zhou, Y., Wang, K., Hou, Y., Hou, R., and Ye, X. (2016). Resveratrol provides neuroprotection by inhibiting phosphodiesterases and regulating the cAMP/AMPK/SIRT1 pathway after stroke in rats. Brain Res. Bull. 121, 255262. doi: 10.1016/j.brainresbull.2016.02.011

Wang, S., Moustaid-Moussa, N., Chen, L., Mo, H., Shastri, A., Su, R., et al. (2014). Novel insights of dietary polyphenols and obesity. J. Nutr. Biochem. 25 (1), 118. doi: 10.1016/j.jnutbio.2013.09.001

Wong, A., and Woodcock, E. A. (2009). FoxO proteins and cardiac pathology. Adv. Exp. Med. Biol. 665, 78-89. doi: 10.1007/978-1-4419-1599-3_6

Wu, Z., Zhao, J., Xu, H., Lyv, Y., Feng, X., Fang, Y., et al. (2014). Maternal quercetin administration during gestation and lactation decrease endoplasmic reticulum stress and related inflammation in the adult offspring of obese female rats. Eur. J. Nutr. 53 (8), 1669-1683. doi: 10.1007/s00394-014-0673-4

Wu, Y. Z., Zhang, L., Wu, Z. X., Shan, T. T., and Xiong, C. (2019). Berberine Ameliorates Doxorubicin-Induced Cardiotoxicity via a SIRT1/p66Shc-Mediated Pathway. Oxid. Med. Cell Longev. 2019:2150394. doi: 10.1155/2019/2150394

Xu, D., Hu, M. J., Wang, Y. Q., and Cui, Y. L. (2019). Antioxidant Activities of Quercetin and Its Complexes for Medicinal Application. Molecules 24 (6), 1123. doi: $10.3390 /$ molecules 24061123

Xue, M., Weickert, M. O., Qureshi, S., Kandala, N. B., Anwar, A., Waldron, M., et al. (2016). Improved Glycemic Control and Vascular Function in Overweight and Obese Subjects by Glyoxalase 1 Inducer Formulation. Diabetes 65 (8), 2282-2294. doi: 10.2337/db16-0153

Yamagata, K. (2019). Polyphenols Regulate Endothelial Functions and Reduce the Risk of Cardiovascular Disease. Curr. Pharm. Des. 25 (22), 2443-2458. doi: 10.2174/1381612825666190722100504

Yang, Y., Paik, J. H., Cho, D., Cho, J. A., and Kim, C. W. (2008). Resveratrol induces the suppression of tumor-derived $\mathrm{CD} 4+\mathrm{CD} 25+$ regulatory $\mathrm{T}$ cells. Int. Immunopharmacol. 8 (4), 542-547. doi: 10.1016/j.intimp.2007.12.006

Yang, Y., Duan, W., Lin, Y., Yi, W., Liang, Z., Yan, J., et al. (2013). SIRT1 activation by curcumin pretreatment attenuates mitochondrial oxidative damage induced by myocardial ischemia reperfusion injury. Free Radic. Biol. Med. 65, 667-679. doi: 10.1016/j.freeradbiomed.2013.07.007

Yeung, F., Hoberg, J. E., Ramsey, C. S., Keller, M. D., Jones, D. R., Frye, R. A., et al. (2004). Modulation of NF-kappaB-dependent transcription and cell survival by the SIRT1 deacetylase. EMBO J. 23 (12), 2369-2380. doi: 10.1038/ sj.emboj.7600244

Yeung, A. W. K., Tzvetkov, N. T., El-Tawil, O. S., Bungau, S. G., Abdel-Daim, M. M., and Atanasov, A. G. (2019). Antioxidants: Scientific Literature Landscape Analysis. Oxid. Med. Cell Longev. 2019:8278454. doi: 10.1155/ 2019/8278454

Yu, L., Li, Q., Yu, B., Yang, Y., Jin, Z., Duan, W., et al. (2016). Berberine Attenuates Myocardial Ischemia/Reperfusion Injury by Reducing Oxidative Stress and Inflammation Response: Role of Silent Information Regulator 1. Oxid. Med. Cell Longev. 2016:1689602. doi: 10.1155/2016/1689602

Yu, Y., Sun, J., Wang, R., Liu, J., Wang, P., and Wang, C. (2019). Curcumin Management of Myocardial Fibrosis and its Mechanisms of Action: A Review. Am. J. Chin. Med. 47 (8), 1675-1710. doi: 10.1142/S0192415X19500861

Zendedel, E., Butler, A. E., Atkin, S. L., and Sahebkar, A. (2018). Impact of curcumin on sirtuins: A review. J. Cell Biochem. 119 (12), 10291-10300. doi: $10.1002 /$ jcb. 27371

Zhang, X., Wu, J., Ye, B., Wang, Q., Xie, X., and Shen, H. (2016a). Protective effect of curcumin on TNBS-induced intestinal inflammation is mediated through the JAK/STAT pathway. BMC Complement Altern. Med. 16 (1), 299. doi: $10.1186 / \mathrm{s} 12906-016-1273-\mathrm{Z}$

Zhang, Y., Dong, H., Wang, M., and Zhang, J. (2016b). Quercetin Isolated from Toona sinensis Leaves Attenuates Hyperglycemia and Protects Hepatocytes in High-Carbohydrate/High-Fat Diet and Alloxan Induced Experimental Diabetic Mice. J. Diabetes Res. 2016:8492780. doi: 10.1155/2016/8492780

Zhang, H., Zhao, Z., Pang, X., Yang, J., Yu, H., Zhang, Y., et al. (2017). MiR-34a/ sirtuin-1/foxo3a is involved in genistein protecting against ox-LDL-induced oxidative damage in HUVECs. Toxicol. Lett. 277, 115-122. doi: 10.1016/ j.toxlet.2017.07.216

Zhang, T., Chi, Y., Ren, Y., Du, C., Shi, Y., and Li, Y. (2019). Resveratrol Reduces Oxidative Stress and Apoptosis in Podocytes via Sir2-Related Enzymes, Sirtuins1 (SIRT1)/Peroxisome Proliferator-Activated Receptor gamma CoActivator 1alpha (PGC-1alpha) Axis. Med. Sci. Monit. 25, 1220-1231. doi: 10.12659/MSM.911714

Zhu, X., Yang, J., Zhu, W., Yin, X., Yang, B., Wei, Y., et al. (2018). Combination of Berberine with Resveratrol Improves the Lipid-Lowering Efficacy. Int. J. Mol. Sci. 19 (12), 3903. doi: 10.3390/ijms19123903

Zordoky, B. N., Robertson, I. M., and Dyck, J. R. (2015). Preclinical and clinical evidence for the role of resveratrol in the treatment of cardiovascular diseases. Biochim. Biophys. Acta 1852 (6), 1155-1177. doi: 10.1016/j.bbadis. 2014.10.016

Conflict of Interest: The authors declare that the research was conducted in the absence of any commercial or financial relationships that could be construed as a potential conflict of interest.

Copyright (๑) 2020 Iside, Scafuro, Nebbioso and Altucci. This is an open-access article distributed under the terms of the Creative Commons Attribution License (CC BY). The use, distribution or reproduction in other forums is permitted, provided the original author(s) and the copyright owner(s) are credited and that the original publication in this journal is cited, in accordance with accepted academic practice. No use, distribution or reproduction is permitted which does not comply with these terms. 